ISSN: 0514-7336

DOI: http://dx.doi.org/10.14201/zephyrus201576159179

\title{
ANIMALES Y RITUAL. LOS REGISTROS FÁUNICOS DE LAS ARAS DE SACRIFICIO DEL ALTO DE GARAJONAY (LA GOMERA, ISLAS CANARIAS)
}

\section{Animals and ritual. Faunal remains from sacrificial altars of El Alto de Garajonay (La Gomera, Canary Islands)}

\author{
Verónica Alberto Barroso*, Juan Francisco Navarro Mederos** y Pablo Castellano Alonso* \\ * Grupo de Investigación TARHA-ULPGC. Edificio Departamental de Humanidades. Campus del Obelisco. Plaza de \\ la Constitución, s/n. 35003 Las Palmas de Gran Canaria. Correo-e: veroalberto1@gmail.com; pcastellanoalon- \\ so@gmail.com \\ ** Dpto. de Prehistoria, Antropología e H. a Antigua-Ull. Campus de Guajara, s/n. 38071 La Laguna. Correo-e: \\ jnavarro@ull.es
}

Recepción: 22/03/2015; Revisión: 6/07/2015; Aceptación: 12/08/2015

BIBLID [0514-7336 (2015) LXXVI, julio-diciembre; 159-179]

\begin{abstract}
Resumen: Este trabajo aborda el significado de los animales en el santuario del Garajonay en La Gomera. Este es un lugar sagrado para las poblaciones prehispánicas de la isla, donde recurrentemente se realizaron celebraciones rituales en un periodo comprendido entre los ss. VII-XII d. C. cal. Dichas actividades se realizaban en las aras de sacrificio donde se quemaban diversos productos primordiales en la subsistencia de los antiguos gomeros. Con este propósito se estudian los repertorios fáunicos, que constituyen la inmensa mayoría de las evidencias allí recuperadas, estableciendo su composición y patrón de procesado. Al efecto, se concluye una conducta netamente estandarizada, definida por el sacrificio exclusivo de animales domésticos, con una rígida selección de las partes anatómicas activas en el ritual. En este proceso el fuego adquiere un protagonismo destacado, contribuyendo a la sacralización de ciertas prácticas sociales. Se analiza asimismo el sentido de tales prácticas en el entramado ideológico de estas poblaciones.

Palabras clave: Arqueología gomera; periodo prehispánico; religión; santuarios; pireos; ofrendas animales.
\end{abstract}

AвSTRACT: This paper addresses the meaning of animals in the sanctuary of Garajonay, in La Gomera. It is a main sacred place for the Prehispanic population, in which they systematically used to perform ritual celebrations within the time period between ss. VII-XII AD cal. These activities took place in the sacrificial altars where various products, essential for the survival of the ancient inhabitants, were burned. For this purpose faunal repertoires have been studied, establishing their composition and processing patterns. It is concluded a standardized behavior defined by the sacrifice of domestic animals, with a rigid selection of skeletal parts actives in the ritual. In that process the fire plays a key role, contributing to the consecration of certain social practices. It has also been analyzed the meaning of such practices in the ideological framework of those populations.

Key words: Archaeology of La Gomera; Prehispanic period; religion; sanctuaries; pyres; animal offerings. 


\section{Introducción ${ }^{1}$}

Las denominadas aras de sacrificio o pireos son un elemento sobresaliente de la arqueología gomera (Fig. 2). Aluden a un aspecto del mundo de las creencias de gran trascendencia para las poblaciones aborígenes que se expresa desde los pequeños conjuntos asociados a los ámbitos domésticos hasta los de nivel superior, de alcance supralocal, materializado en este caso en el punto geográfico más relevante de la isla, la cima del Garajonay. En ellas tiene lugar la celebración de prácticas rituales a partir de la cremación de diversos productos, garantes de la subsistencia, que son elevados a la categoría de ofrendas. Los numerosos santuarios identificados en emplazamientos elevados revelan que los aborígenes gomeros realizaban sacrificios a su divinidad en la cima de montańas, roques, crestas y acantilados, definiendo un complejo entramado de sitios ceremoniales con una fuerte estandarización de las actividades que allí se realizaban y donde el Alto de Garajonay debió ocupar una posición preeminente. Allí parecen confluir los límites territoriales de los primitivos bandos que fraccionaban la isla. También las fuentes escritas apuntan a que se trataba de un territorio sagrado e inviolable, donde se refugiaba la población en caso de peligro (Navarro, 1992, 2003, 2004, 2006 y 2007; Navarro et al., 2001a, 2001b y 2001c; Hernández y Navarro, 2011-12) (Fig. 2).

En la isla, las aras de sacrificio son construcciones de piedra seca, constituidas por una estructura o armazón general y pequeños receptáculos en su interior donde se realizaba la combustión. Lo más

1 Este trabajo fue realizado en el marco de dos proyectos subvencionados por el o. A. Parques Nacionales (Ministerio de Agricultura y Medio Ambiente), cuyo IP fue J. F. Navarro Mederos: “Arqueología de las Montañas. Investigaciones Arqueológicas en el Alto de Garajonay, isla de La Gomera" (2001-2004) e "Inventario arqueológico y su aplicación a la conservación e incorporación a los programas interpretativos del Parque Nacional de Garajonay" (20042005). Agradecemos al extenso equipo de investigadores que participaron en ambos proyectos, al personal del Parque Nacional de Garajonay, particularmente, a su director Ángel Fernández, y al personal del Museo Arqueológico de La Gomera. Además estamos en deuda con J. Velasco por sus valiosos comentarios, así como con los evaluadores de este trabajo, cuyas precisas y clarificadoras sugerencias han contribuido a mejorarlo.

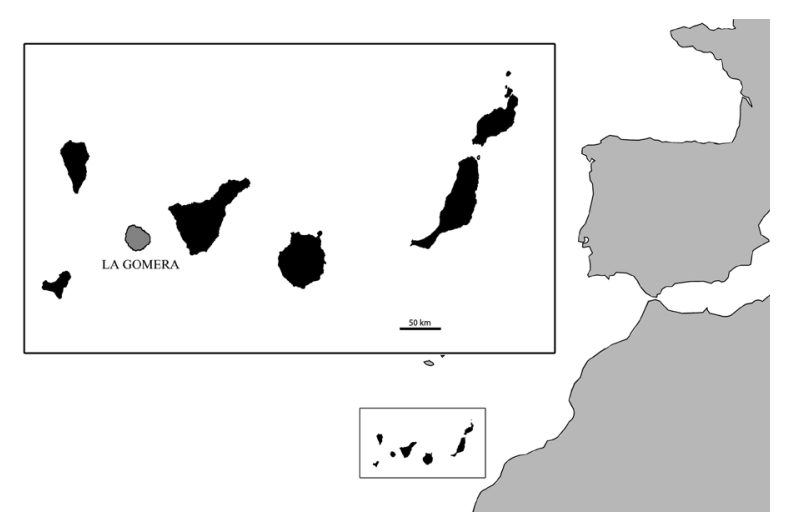

FIg. 1. Situación de La Gomera en el Archipiélago Canario.

usual es que formen conjuntos ubicados en puntos estratégicos del territorio, distinguiéndose entre tipos simples y compuestos según la complejidad de la obra, dimensiones y número de cavidades o focos de combustión. Dentro de las compuestas, las del Alto de Garajonay representan una tipología única en la isla caracterizada por una construcción más sólida, laboriosa y complicada que las de cualquier otro grupo ${ }^{2}$. Entre los productos consumidos en la celebración cabría destacar la relevancia de la cabaña ganadera ${ }^{3}$.

En relación con esta significación se presentan los resultados del estudio de los restos de fauna terrestre procedentes de dos aras de la cima del Garajonay, con el propósito de profundizar en su significado, sumándolos a los ya disponibles para otros conjuntos de la isla y del archipiélago ${ }^{4}$.

2 De ahí que se haya convenido en denominar a esta categoría 'aras tipo Garajonay'.

3 Prácticamente la totalidad del material recuperado son huesos de animales, aunque también se ha localizado una serie reducida de semillas de cebada y dátiles, entre otras, que revelan asimismo la participación de los productos vegetales en este tipo de prácticas (Morales et al., 2009).

4 Las aras de sacrificios son manifestaciones que, tal y como han sido descritas, solo se conocen en La Gomera y El Hierro, aunque existen indicios para pensar que en otras islas también pudieron existir, quizá con unas características diferentes. Los únicos estudios zooarqueológicos disponibles se refieren a los materiales de otro conjunto de aras de La Gomera, localizadas en el lomo del Piquillo, en este caso en un ambiente de costa (Navarro et al., 2001b), y los procedentes de un ara de El Julán, en El Hierro (Alberto, 2002). 


\section{El yacimiento}

El Alto de Garajonay es el centro y el punto más elevado de La Gomera, con 1487 msnm. En la crestería se conservan los vestigios de lo que antaño fuera un conjunto excepcional, hoy parcialmente destruido por las diversas intervenciones habidas desde mediados del s. xx. Del complejo original persisten piedras con grabados, reutilizadas en construcciones modernas, y los restos de tres aras de sacrificio de proporciones superiores a lo habitual en el resto de la isla.

Este trabajo se centra en el análisis de los restos fáunicos de las denominadas estructuras A y c. La primera de ellas ubicada muy cerca de la cima y la segunda en la propia cúspide. Su excavación ha proporcionado un elevadí-

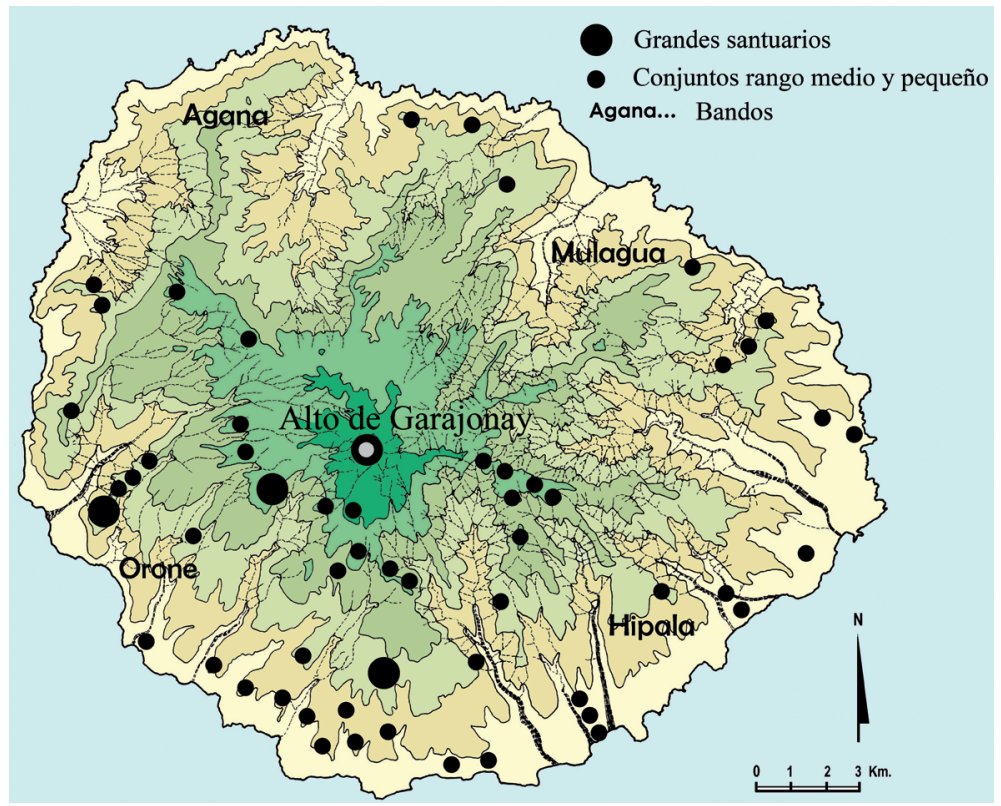

FIG. 2. Distribución espacial de las aras de sacrificio en la isla. simo volumen de restos óseos, de ahí su importancia como elemento esencial para la definición y caracterización del ritual y, por ende, de las prácticas sociales que se suscitan en torno a este tipo de manifestaciones (Navarro et al., 2002 y 2005). Para el encuadre cronológico de estas estructuras se dispone de nueve dataciones, de las cuales las más fiables abarcan un lapso temporal entre $1590 \pm 60 \mathrm{BP}^{5}$ y $990 \pm 40 \mathrm{BP}^{6}$ (Hernández y Navarro, 2011-12) 7 .

Beta-206020 $1590 \pm 60$ вр -24.1 о/оо $1600 \pm 60$ вр. Radiometric-Standard delivery (with extended counting). Material: Adenocarpus foliolosus. $2 \sigma$ calibration: Cal AD 340 to 600 (Cal вр 1610 to 1350 ).

6 Beta-206016990 440 вр -24.4 о/оо $1000 \pm 40$ вр. AMs-Standard delivery. Material: Adenocarpus foliolosus. $2 \sigma$ calibration: Cal AD 980 to 1060 (Cal BP 970 to 890) and Cal AD 1080 to 1150 (Cal BP 860 to 800 ).

Dado el estado calcinado de los huesos, se optó por datar materiales vegetales carbonizados. Para comprobar la fiabilidad de diferentes plantas y sus partes se seleccionaron tres tipos de muestras: semillas de cebada (Hordeum vulgare), carbón de codeso (Adenocarpus foliolosus) y carbón de pino (Pinus canariensis). El codeso y las semillas de cebada proporcionaron fechas similares, mientras que el carbón de madera de pino resultó entre 200 y 400 años más antiguo que la cebada o codeso de su mismo contexto, incidiendo en los problemas de envejecimiento ampliamente detectados en las muestras arqueológicas de carbón de pino canario.

La estructura A, que no se conserva completa, es una construcción de tipo tumular de grandes dimensiones que abarca más de $30 \mathrm{~m}^{2}$ y aproximadamente $1,80 \mathrm{~m}$ de alto, elaborada con tierra $\mathrm{y}$ piedras recolectadas en el entorno (Fig. 3). En su parte superior define dos plataformas escalonadas, con una diferencia de unos $40 \mathrm{~cm}$ entre ellas. La plataforma inferior, en el lado de sotavento, resulta la más adecuada para las actividades que impliquen fuego y humo, de ahí la presencia de los focos de combustión y las concentraciones de fauna quemada, con excepción de un foco que se ubica en la superior. Dentro del conjunto se procedió a la excavación y estudio de un sector individualizado de la plataforma inferior, denominado subestructura A-1. Esta destaca por su posición prominente con $1,4 \mathrm{~m}$ sobre el nivel del suelo, producto de la adición de la plataforma-base de 1,1 m y el ara o pireo sensu stricto de unos $0,30 \mathrm{~m}$. En ella, siguiendo un eje NO-SE de unos $4 \mathrm{~m}$ de longitud, se disponen tres cavidades de combustión unidas entre sí, designadas foco 1, 2 y 3 (Fig. 4).

La estructura C corresponde a una construcción de planta oval, cuyas dimensiones en planta abarcan unos $56 \mathrm{~m}^{2}$ y entre $0,30 \mathrm{~m}$ y $1 \mathrm{~m}$ de altura, dependiendo del desnivel e irregularidades del terreno de 


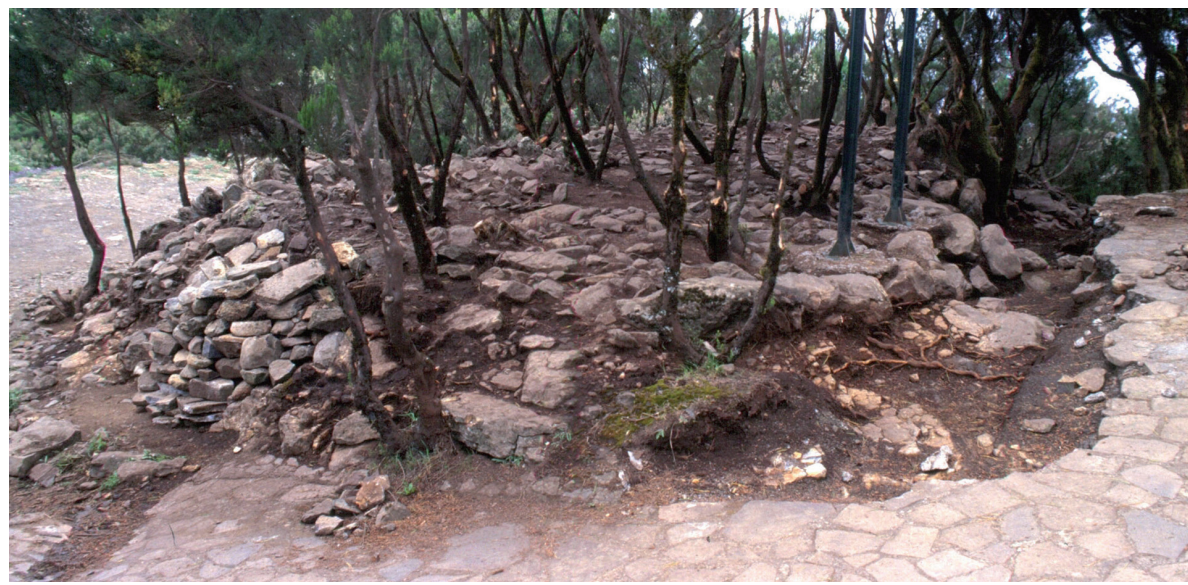

FIG. 3. Vista general de la Estructura A.

La muestra destaca por el elevadísimo número de piezas, intensamente fracturadas por el fuego, que supera los 500.000 restos (Fig. 6). De ahí que haya sido necesario trabajar con unidades de peso y solo en casos específicos se han cuantificado los elementos susceptibles de una caracterización certera. En cualquier caso, los resultados obtenidos permiten comparaciones y conclusiones generales, pues los restos identificados resultan totalmente

acogida ${ }^{8}$. Presenta, a su vez, dos zonas bien diferenciadas: una plataforma perimetral, rellena de piedras pequeñas y medianas, circunscrita por grandes bloques elipsoidales hincados, y una plataforma central, sobreelevada unos $50 \mathrm{~cm}$ con respecto a la anterior, constituida por un relleno similar e igualmente delimitada por grandes piedras. En origen presentaba tres recintos para la combustión, dos en el área meridional de la plataforma perimetral, denominados pireo SW y SE, y otro en la plataforma central. En concreto, el análisis de la fauna se ha centrado en los materiales del pireo sw (Fig. 5).

\section{El repertorio fáunico}

Los materiales de estudio presentan unas características muy específicas que lo diferencian de los repertorios fáunicos insulares de consumo. Sin duda, el perfil de la muestra responde a la naturaleza de los actos sociales en los que intervienen estos animales, dando lugar a un registro particular (Brück, 1999; Davis, 2008; Morales, 2008), lo que ha condicionado de forma decisiva el tipo de análisis realizado?.

8 Al iniciar los trabajos arqueológicos el ara estaba oculta bajo un mirador y un vértice geodésico. Dicho elemento destruyó el área septentrional, de ahí la dificultad para conocer con exactitud su diámetro N-s.

9 La determinación anatómica y taxonómica se ha efectuado mediante comparación con las colecciones de referencia propias. Para la diferenciación entre cabras y representativos del conjunto. Otros rasgos distintivos se refieren a la exclusiva presencia de cabras y ovejas y, en menor medida, de cerdos ${ }^{10}$, utilizándose exclusivamente cabezas y patas.

Estas cualidades, en especial el elevado índice de fracturación de los huesos, limitan en gran medida su estudio. En este panorama ha de situarse el hecho de que la mayoría corresponde a cabras y ovejas, dificultando la discriminación entre géneros dada la similitud morfológica de sus esqueletos. Por esta razón, una proporción destacada de los restos analizados se clasifican bajo el término genérico de ovicaprinos. Además, en una muestra en la que los restos no superan la condición de meras esquirlas, se reduce notablemente la posibilidad de precisar las variables de sexo y edad, información fundamental a la hora de establecer el significado

ovejas se han seguido los criterios de Boessneck (1980). La estimación de la edad se ha establecido según el grado de fusión epifisaria (Silver, 1980), también se ha considerado el grado de desarrollo (espesor) de la cortical de los fragmentos de cráneo, metápodos y falanges y en menor medida el estado de erupción y desgaste de las piezas dentales (Payne, 1973 y 1987; Grant, 1982). Para la estimación del NMI se ha considerado la representación de los huesos pares (Clason, 1972), incrementando la cuantificación a partir de otras piezas según el grado de fusión epifisaria.

10 Entre la fauna se han recuperado 9 restos de animales silvestres como lagartos y conejos, irrelevantes en términos cuantitativos, cuyo origen resulta claramente intrusivo y ajeno al contexto ritual al que pertenecen las restantes evidencias. 
de los animales en el ámbito de las creencias. Otro de los problemas derivado de las peculiaridades del registro es la imposibilidad de abordar la biometría de los animales, no solo por el elevado índice de fracturación, sino también por los importantes procesos de deformación y contracción debidos al fuego. Por otro lado, al tratarse de registros limitados desde el punto de vista anatómico se facilita el proceso de identificación de la pieza

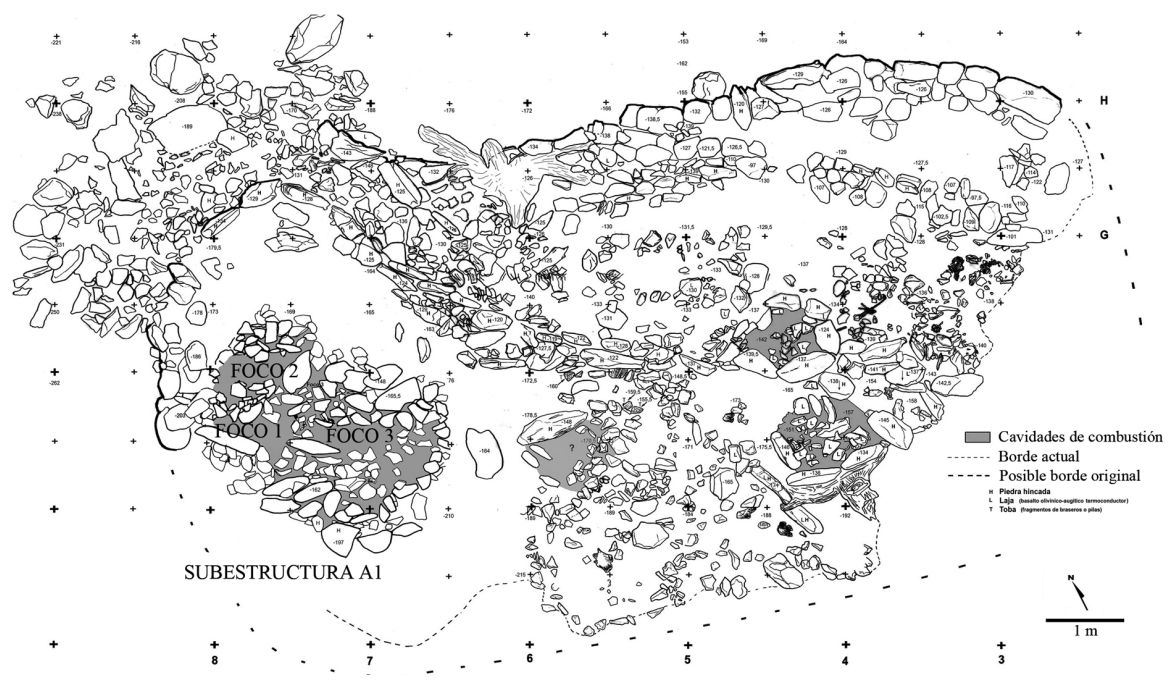
esquelética, toda vez que

Fig. 4. Planta de la Estructura A.

la arquitectura ósea de

los huesos resulta fácilmente reconocible. Para ello se ha recurrido, en los casos que no conservan elementos diagnósticos, al examen pormenorizado de las tipometrías de las secciones diafisarias, permitiendo su distinción en una proporción muy alta de los fragmentos ${ }^{11}$. Asimismo, el proceso de identificación de los repertorios se ha beneficiado de los resultados obtenidos en los estudios previos de las series del Lomo del Piquillo y El Julán, donde registros de similar composición y características apoyan las conclusiones alcanzadas en este caso, o incluso del examen in situ de los restos óseos de una elevada proporción de las aras gomeras, repartidas por distintos puntos de la isla, que apuntan en la misma línea.

En la estructura A, la serie seleccionada la componen los huesos recuperados del interior de las tres cavidades de combustión de la subestructura A-1, en contraposición a la ingente cantidad de restos óseos esparcido por toda la construcción. Por su parte, para la C se ha optado por una muestra proveniente tanto del interior como del exterior inmediato de la cavidad de combustión so. En cualquier caso, en ambas aras el origen de los restos no es otro que

11 El hecho de que exista un grupo de indeterminados viene provocado en su gran mayoría porque no se han considerado aquellos fragmentos inferiores a $5 \mathrm{~mm}$, salvo en algunos repertorios específicos como el de los dientes. los deshechos de la práctica ritual, por lo que todo el material proviene de las cavidades que sucesivamente se van vaciando de los residuos por los procesos de limpieza y adecuación de la zona funcional de combustión ${ }^{12}$.

El montante global de evidencias recuperadas hasta el momento es de $18.450 \mathrm{~g}$, correspondiendo $12.020 \mathrm{~g}$ a la estructura A y $6.430 \mathrm{~g}$ a la estructura C. De esta cantidad $7.275 \mathrm{~g}$ fueron seleccionados para su estudio en la estructura A y $1.279,5 \mathrm{~g}$ de la C (Fig. 7).

En el ejemplo de la estructura A la muestra examinada supera la mitad del repertorio óseo recuperado hasta ahora. Dentro de este contexto se producen notorias diferencias entre el contenido de cada uno de los focos, siendo el 3 el que aporta un mayor volumen de restos y el que, sin duda, posee una participación más destacada dentro del entramado de zonas de combustión del ara. A mucha distancia se sitúan los focos 1 y 2 , con un mayor alcance del primero frente al segundo, cuyas evidencias en el balance general resultan relativamente

12 En un programa de control efectuado entre ambos conjuntos, esto es, los emplazados dentro y fuera de los focos de combustión, se ha comprobado que su composición y características son semejantes en todos los aspectos considerados y que no existen diferencias entre ambos repertorios. 


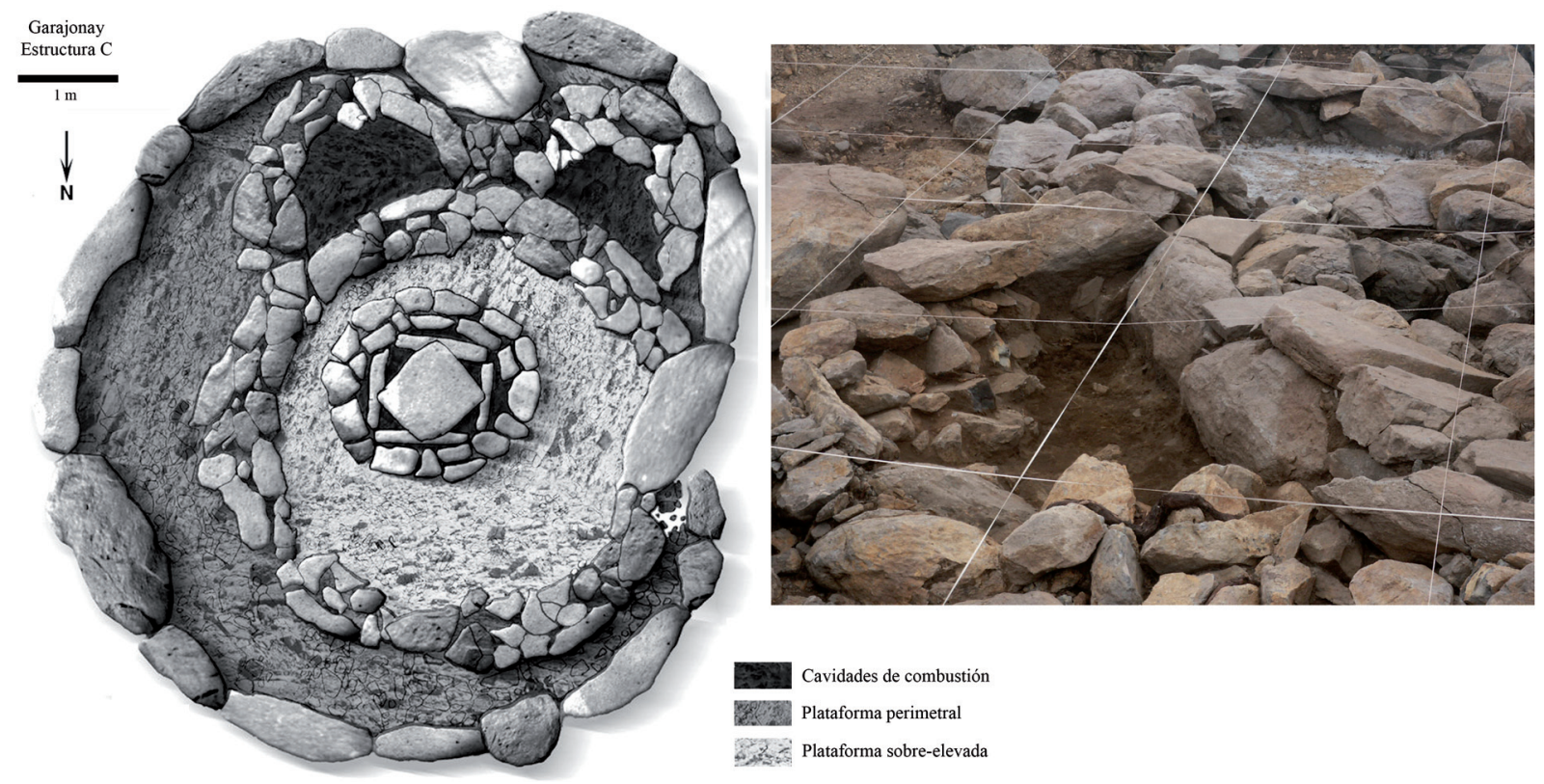

FIG. 5. Recreación de la Estructura C y detalle de los pireos SW y SE.

escasas. Pese a ello, esta situación se atenúa en cierto modo con la aportación de los restos que se dispersan por el exterior de los focos. En cuanto a la $\mathrm{C}$, solo se ha estudiado un repertorio parcial correspondiente a una única cavidad de combustión, cuyos restos significan aproximadamente una quinta parte del volumen total recuperado.

\section{Estrictos criterios de selección}

Las especies utilizadas provienen de la cabaña ganadera de los antiguos gomeros: cabras, ovejas y cerdos. Se trata de una composición similar a la de otras aras, en las que se reitera el carácter doméstico de la fauna empleada en el ritual. No obstante, un análisis más detallado permite establecer una diferencia con respecto a otros ejemplos. Así, mientras que en los casos precedentes solo se han identificado cabras y ovejas (Alberto, 2002; Navarro et al., 2001b), en las aras del Garajonay se constata por primera vez el uso de $\operatorname{cerdos}^{13}$.

13 Para el ejemplo de El Hierro existen algunas referencias que aluden a la presencia de cerdos en las aras (Jiménez, 1993; Steiner, 2007 y 2008), aunque estas no se sustentan en estudio alguno del material. Al contrario, en

\subsection{Cabras y ovejas}

Es el primer grupo en cuanto a volumen de participación, constituyendo casi la totalidad de la muestra analizada. Como se ha indicado, las condiciones de la muestra hacen que la identificación precisa entre cabras y ovejas resulte muy baja. En general, los huesos más utilizados para la discriminación han sido las falanges, seguidas por el naviculocuboideo, la porción proximal de los metápodos y, de forma testimonial, el cóndilo mandibular. La atribución específica solo se ha realizado en 102 restos, de los que $83(81,37 \%)$ corresponden a la estructura A y $19(18,62 \%)$ a la estructura $\mathrm{C}^{14}$. En el primer caso, 51 restos corresponden a cabras $(61,44 \%)$ y 32 a ovejas $(38,55 \%)$. En el segundo, 6 corresponden a cabras $(31,57 \%)$ y 13 a ovejas $(68,42 \%)$ (Figs. 8 y 9$)$.

los análisis zooarqueológicos realizados hasta ahora no se ha producido tal identificación (Alberto, 2002).

14 Para este cómputo se han dejado al margen todas las evidencias de cuernos de cabra cuya identificación resulta obvia, provocando una notable desproporción cuantitativa que podría distorsionar la comparación. En este sentido, hay que indicar que las ovejas prehispánicas procedentes del $\mathrm{N}$ de África carecen de cuernos y lana. 
Según se desprende de estos resultados, existe cierta desigualdad en la frecuencia de participación entre ambas estructuras. Así, mientras en la A predominan los restos de cabras, en la C se invierte la proporción, siendo favorable a las ovejas ${ }^{15}$.

\subsection{Cerdos}

Entre los huesos estudiados solo se han identificado 36 fragmentos de cerdo, de los cuales 27 corresponden a la estructura A y 9 a la c. Destaca que en la estructura A la mayor proporción de restos proceda de la cavidad 1 y no de la 3, como cabría esperar por el cuantioso volumen de restos recuperados en esta última ${ }^{16}$ (Figs. 8 y 9). Los elementos anatómicos más relevantes para la identificación han sido los del esqueleto craneal, destacando las mandíbulas y maxilares, así como esquirlas de dentición. Para el esqueleto postcraneal solo se ha producido la identificación de las terceras falanges y un extremo proximal de metápodo ${ }^{17}$.

\section{Requisitos para el sacrificio}

La estimación del sexo y la edad de los animales sacrificados en una muestra de este tipo resulta asimismo una tarea compleja. Esto implica que los

15 Estos datos no deben considerarse conclusiones definitivas con respecto a la contribución de ambos géneros, pues los valores se obtienen de la determinación de fragmentos óseos y no del NMI. No obstante, son válidos como valores de referencia a confirmar en futuros trabajos que comprendan la totalidad de los restos recuperados en las excavaciones arqueológicas.

16 Sin embargo, dicha circunstancia, por el momento, no es concluyente en el sentido de una contribución desigual de especies animales por cavidades, pues, como en el caso de cabras y ovejas, su distinción se realiza sobre la base de restos anatómicos y no sobre el NMI, aspecto que podría provocar cierta sobrevaloración de la frecuencia de participación en las distintas cavidades.

${ }_{17}$ No obstante, en el análisis de control realizado con el material del exterior de las cavidades de combustión de la estructura A, se ha documentado la presencia de metápodos y falanges segundas de cerdo.

datos obtenidos sean parciales y en muchas ocasiones no deriven de un análisis exacto, sino de hipótesis sustentadas en indicios biológicos menos precisos que otros criterios anatómicos. Pese a ello, el volumen de material estudiado es tan elevado que aporta una visión adecuada del patrón de sacrificio en lo que a edad y sexo de los animales se refiere.

Para la reconstrucción de los patrones de sacrificio y las actividades rituales que se llevan a cabo en las aras se ha atendido al establecimiento de pautas de explotación en relación con el desarrollo de los animales que integran la cabaña ganadera y su función socioeconómica. A tal efecto, en un importante volumen de restos analizados se ha podido constatar su plena madurez ${ }^{18}$. Ante la imposibilidad de señalar porcentajes definitivos sobre la relación infantiles/juveniles/adultos, entre los huesos que no han podido ser baremados existen firmes indicios para admitir que muchos de ellos podrían pertenecer a ejemplares inmaduros, con lo que la

18 No obstante, se dan ciertos problemas a la hora de distinguir entre animales totalmente adultos y animales desarrollados, pero que no alcanzan la madurez total, y si bien la ratio es favorable al grupo de los adultos pudiera suceder que algunos elementos del grupo de los juveniles hubieran pasado desapercibidos dentro de la primera categoría. En cualquier caso, se trataría siempre de animales muy próximos al estadio adulto y que han sido clasificados como animales desarrollados. 
166 Verónica Alberto, Juan Francisco Navarro y Pablo Castellano / Animales y ritual. Los registros fáunicos de las aras...

\begin{tabular}{|c|c|c|c|c|}
\hline & \multicolumn{3}{|c|}{ Estructura A } & Estructura C \\
\hline Material recuperado $(\mathrm{g})$ & \multicolumn{3}{|c|}{12020} & 6430 \\
\hline \multirow{3}{*}{ Material estudiado (g) } & \multicolumn{3}{|c|}{7275} & \multirow{3}{*}{1279} \\
\hline & Cavidad 1 & Cavidad 2 & Cavidad 3 & \\
\hline & 1030 & 324 & 5921 & \\
\hline$\%$ estudiado & \multicolumn{3}{|c|}{$60,52 \%$} & $19,89 \%$ \\
\hline
\end{tabular}

De los datos obtenidos hasta el momento, se concluye que para el caso de cabras y ovejas el porcentaje más elevado de individuos sacrificados lo representan las hembras desarrolladas o ya adultas, destacando que en este grupo de edad no se haya constatado ningún ejemplar masculino. A continuación se sitúan los individuos infantiles, enFIG. 7. Reparto de las evidencias según su peso en gramos. tre los que se encuentran también los neonatos, habiéndose identificado tan solo 142 restos en la estructura a y 46

participación de este segmento de edad sería algo mayor de lo que a priori se puede concluir de los datos que aquí se recogen.

Por su parte, la determinación del sexo se ha establecido principalmente entre los individuos adultos, tomando como referencia las tallas y la robustez, sobre todo a partir de los restos del esqueleto postcraneal. Para este aspecto los problemas se repiten por las condiciones de fragmentación y representación anatómica del registro. De cualquier forma y aunque no se pueda disponer de una cuantificación absoluta, como en el caso de la edad, se han establecido criterios de identificación de nivel intermedio. El resultado es un predominio de las hembras frente a los machos, si bien es posible que estos estén representados a través de parte de los infantiles en los que es más difícil precisar el sexo al que pertenecen. en la c. Cabe resaltar que, entre los infantiles, los neonatos no son tan abundantes como se ha comprobado en el contexto de El Julán en El Hierro (Alberto, 2002), y en conjunto los infantiles son menos representativos que los ejemplares desarrollados. Precisamente, entre los animales no desarrollados de la estructura $\mathrm{A}$, se han registrados tres casos con las condiciones para considerar con relativa fiabilidad su pertenencia a ejemplares masculinos. De cualquier modo, el grupo de los desarrollados, adultos o a punto de entrar en este estadio, supera ampliamente el de los infantiles o inmaduros.

Por lo que respecta a los cerdos, la totalidad de los restos identificados corresponden a ejemplares inmaduros, infantiles o juveniles, que aún no han alcanzado la plena madurez. En cuanto al sexo, es difícil pronunciarse debido al escaso volumen de material que supone la muestra.

\begin{tabular}{|c|c|c|c|c|}
\hline ESTRUCTURA A & $\begin{array}{c}\text { CAVIDAD DE } \\
\text { COMBUSTIÓN } 1\end{array}$ & $\begin{array}{c}\text { CAVIDAD DE } \\
\text { COMBUSTIÓN } 2\end{array}$ & $\begin{array}{c}\text { CAVIDAD DE } \\
\text { COMBUSTIÓN } 3\end{array}$ & TOTAL \\
\hline Cabra & $\begin{array}{l}590 \mathrm{~g} \text { de cuernos } \\
1 \text { frag. metacarpo } \\
2 \text { frags. metatarso } \\
4 \text { falanges } \\
\qquad(13,72 \%) \\
\end{array}$ & $\begin{array}{l}240 \mathrm{~g} \text { de cuerno } \\
1 \text { carpo } \\
1 \text { tarso } \\
\quad(3,92 \%)\end{array}$ & $\begin{array}{l}491 \text { g de cuerno } \\
5 \text { naviculocuboide } \\
2 \text { frags. metacarpo } \\
30 \text { falanges }+5 \text { frags. falanges } \\
\quad(82,53 \%) \\
\end{array}$ & $\begin{array}{l}1321 \mathrm{~g} \text { de cuernos } \\
51 \text { restos óseos }\end{array}$ \\
\hline Oveja & $\begin{array}{l}1 \text { falange } \\
\qquad(3,12 \%)\end{array}$ & $\begin{array}{l}1 \text { falange } \\
1 \text { frag. mandíbula } \\
\quad(6,25 \%)\end{array}$ & $\begin{array}{l}1 \text { frag. mandíbula } \\
1 \text { carpo } \\
20 \text { falanges }+7 \text { frags. falanges } \\
(90,62 \%) \\
\end{array}$ & 32 restos óseos \\
\hline Cerdo & $\begin{array}{l}15 \text { frags. de cráneos } \\
1 \text { frag. maxilar } \\
2 \text { frags. mandíbula } \\
3 \text { frags. dentición } \\
\quad(77,77 \%)\end{array}$ & $\begin{array}{c}1 \text { frag. de dentición } \\
(3,70 \%)\end{array}$ & $\begin{array}{l}1 \text { frag. cráneo } \\
2 \text { frags. mandíbula } \\
2 \text { falanges } \\
\qquad(18,51 \%)\end{array}$ & 27 restos óseos \\
\hline TOTALES & $\begin{array}{l}590 \mathrm{~g} \text { de cuerno } \\
29 \text { restos óseos }\end{array}$ & $\begin{array}{l}240 \mathrm{~g} \text { de cuerno } \\
5 \text { restos óseos }\end{array}$ & $\begin{array}{l}491 \mathrm{~g} \text { de cuerno } \\
76 \text { restos óseos }\end{array}$ & $\begin{array}{l}1321 \mathrm{~g} \text { de cuernos } \\
110 \text { restos óseos }\end{array}$ \\
\hline
\end{tabular}

FIG. 8. Determinación especifica de la Estructura A. 
En general, el modelo expresado se encuentra dentro de los patrones de explotación de la cabaña ganadera más frecuentemente constatados entre las poblaciones aborígenes del Archipiélago (Pais, 1996; Galván et al., 1999; Alberto, 2004). En lo concerniente a cabras y ovejas, tales pautas de sacrificio evidencian el predominio de una explotación encaminada,

\begin{tabular}{|c|c|c|c|}
\hline ESTRUCTURA C & NIVEL I & NIVEL II & $\begin{array}{c}\text { TOTAL Especie/ } \\
\text { General }\end{array}$ \\
\hline Cabra & $14 \mathrm{~g}$ de cuerno & $\begin{array}{c}44 \mathrm{~g} \text { de cuerno } \\
1 \text { naviculocuboide } \\
5 \text { frags. falanges }\end{array}$ & $\begin{array}{c}58 \mathrm{~g} \text { de cuerno } \\
6 \text { restos óseos }\end{array}$ \\
\hline Oveja & - & $\begin{array}{c}1 \text { naviculocuboide } \\
12 \text { frags. falange }\end{array}$ & 13 restos óseos \\
\hline Cerdo & - & $\begin{array}{c}4 \text { frags. cráneo } \\
1 \text { frag. maxilar } \\
1 \text { frag. mandíbula } \\
3 \text { frags. dentición }\end{array}$ & 9 restos óseos \\
\hline TOTALES & $14 \mathrm{~g}$ de cuerno & $\begin{array}{c}44 \mathrm{~g} \text { de cuernos } \\
28 \text { restos óseos }\end{array}$ & $\begin{array}{c}58 \mathrm{~g} \text { de cuerno } \\
28 \text { restos óseos }\end{array}$ \\
\hline
\end{tabular}

FIG. 9. Determinación específica de la Estructura C. en primera instancia, a la producción de leche y derivados. En este modelo, los rebaños están constituidos en su mayoría por hembras adultas, en pleno rendimiento económico, mientras que los animales poco productivos se sacrifican para el consumo cárnico. En esta línea de explotación también se entiende el papel atribuido a los recién nacidos, de los cuales se separan los ejemplares más aptos para garantizar la renovación y reproducción de las manadas, produciéndose el sacrificio de los individuos desechados o sobrantes en este proceso de selección. Por ello, un número importante de machos se sacrifica a edades muy tempranas ya que fundamentalmente se crían para la reproducción, aunque sin olvidar su papel en el aporte de productos cárnicos en momentos específicos.

Por lo que se refiere al patrón de sacrificio de los cerdos, se caracteriza por el uso de animales infantiles/juveniles, a semejanza de lo documentado en los espacios de habitación entre los repertorios de consumo. Tradicionalmente, para la explotación de la cabaña porcina en época prehispánica se ha planteado un aprovechamiento principal cuando los animales han alcanzado un rendimiento cárnico óptimo, esto es, entre 10-12 meses (Pais, 1996). No obstante, en los registros de consumo de algunas islas es muy frecuente la presencia de animales infantiles de muy corta edad.

Estos patrones han sido descritos para los sistemas de aprovechamiento animal más directamente vinculados con la producción de alimentos y bienes de primera necesidad ${ }^{19}$. Por tanto, se manifiesta una

19 Se habla en términos generales de patrones de explotación para los aborígenes del archipiélago porque, concordancia plena entre los esquemas de gestión de los animales domésticos en distintos planos del sistema productivo, en este caso concreto más vinculado al ámbito de los mecanismos ideológicos desplegados para mantener y garantizar el orden social, en el sentido más amplio del concepto.

\section{La parte por el todo}

Se advierte una notable selección de las regiones anatómicas que conlleva una restricción esquelética estricta y netamente normalizada. Es evidente que en lo que conocemos del ritual no se empleaban los animales completos, sino ciertas partes de su cuerpo, comportamiento vinculado al planteamiento ideológico que rige las actividades celebradas en estos enclaves y los objetivos o finalidades pretendidos. En este sentido, como sucede en otras aras, se produce el empleo exclusivo de cabezas y extremos de las patas: cráneos, carpos, tarsos, metápodos y falanges (Figs. 10 y 11).

Un aspecto destacado es la diferencia que se registra en los porcentajes referidos a los cuernos, dándose una frecuencia mayor en la estructura $\mathrm{A}$ con un $8,4 \%$ frente al $4,5 \%$ de la c. Cabe señalar la mayor participación de restos de ovejas documentada en la estructura c, que si bien referíamos

por el momento, no existen estudios específicos para la Prehistoria de La Gomera. De cualquier modo, se ha comprobado que se trata de mecanismos socioeconómicos ampliamente difundidos entre las distintas sociedades prehispánicas de Canarias. 
168 Verónica Alberto, Juan Francisco Navarro y Pablo Castellano / Animales y ritual. Los registros fáunicos de las aras...

\begin{tabular}{|c|c|c|c|c|c|}
\hline ESTRUCTURA A & CAVIDAD 1 & CAVIDAD 2 & CAVIDAD 3 & TOTAL g & \% \\
\hline Cuerno & 132 & 16 & 465 & 613 & 8,4 \\
\hline Cráneo & 148 & 54 & 1230 & 1432 & 19,7 \\
\hline Mandíbula & 32 & 11 & 187 & 230 & 3,2 \\
\hline Pieza dental & 37 & 11 & 111 & 159 & 2,2 \\
\hline Hioides & 2 & - & 10 & 12 & 0,2 \\
\hline Carpo/Tarso & 29 & 18 & 210 & 257 & 3,5 \\
\hline Metápodo & 319 & 112 & 2090 & 2521 & 34,6 \\
\hline Falange & 91 & 40 & 581 & 712 & 9,8 \\
\hline Indeterminado & 240 & 62 & 1037 & 1339 & 18,4 \\
\hline TOTALES & 1030 & 324 & 5921 & 7275 & 100 \\
\hline
\end{tabular}

en la $\mathrm{A}$, esto es, el 3,8\% frente al 2,2 \%. Ello pudiera interpretarse como la posibilidad de que en la estructura c se quemen más cabezas que en la $\mathrm{A}$, pues las semejantes condiciones de preservación no respaldan fenómenos de conservación diferencial. En cuanto a las restantes unidades anatómicas, los valores alcanzados en ambas estructuras son muy semejantes (Fig. 12).

Hay que destacar que este proceder selectivo en

que no debe considerarse una conclusión definitiva sobre una participación diferencial de cabras y ovejas en los distintos espacios rituales, parece concordar con el hecho de que la presencia de cuernos es más importante precisamente donde se ha registrado una mayor frecuencia de restos de cabras a partir de otras unidades anatómicas y, al contrario, son menos significativos en aquel espacio en el que las ovejas se sitúan por encima. También destaca la diferente proporción de restos de dentición registrada entre una estructura y otra, dándose la circunstancia de que, aun siendo muy bajo el porcentaje que representan las piezas dentales, en la estructura C significa casi el doble del volumen constatado relación con el cuerpo del animal es un fenómeno ampliamente extendido, incluso en lo que respecta a otros tipos de prácticas rituales de las poblaciones prehispánicas del archipiélago.

\section{El tratamiento carnicero}

Una vez se produce la elección del animal, este es sometido a un tratamiento sumamente específico del que solo es posible reconstruir los gestos relacionados con aquellas porciones que se queman en las aras. En contraposición, se ignora el tipo de manipulación a la que se somete el resto del ejemplar, como también se desconoce su destino. Con relación a este aspecto, a partir de la representación anatómica y de las huellas de corte presentes en algunos de los restos estudiados, se identifican las acciones debidas a la desmembración del cuerpo que han de vincularse a la restricción esquelética que se registra. Tal circunstancia revela que las víctimas elegidas son desarticuladas con anterioridad a la fase de cremación y que, independientemente del

FIG. 11. Peso en gramos de los elementos anatómicos por niveles. 
papel que desempeñe el resto del cuerpo en la actividad ritual, en la cavidad de combustión solo se incluyen ciertas partes del animal. Según se desprende de los restos analizados, la sección de la cabeza se produce justo por la región occipital, en la misma base del cráneo. Corresponde a un corte certero y preciso que solo afectaría a la cabeza. Por

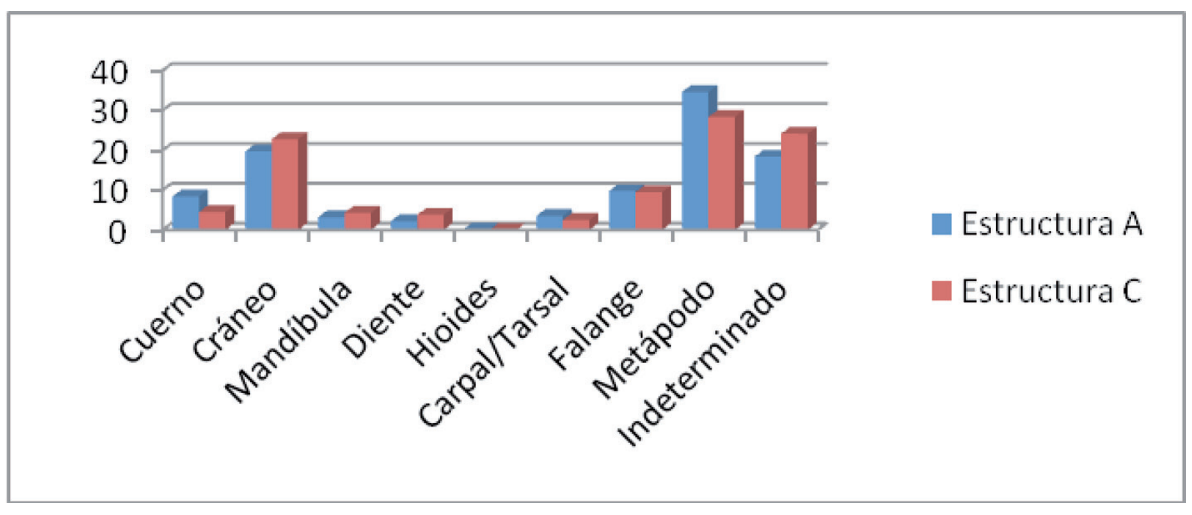

FIG. 12. Representación porcentual de las unidades anatómicas.

este motivo en la muestra

no se constatan fragmentos de la porción cervical, ni tan siquiera en lo que atañe al atlas o al axis como primeras unidades vertebrales del raquis. Para el caso de las patas, las porciones se obtienen a partir de la desarticulación de las extremidades en la región de los carpos y de los tarsos. Se constata un acto de despiece sumamente medido y experto que se repite de manera sistemática sin variaciones. En lo que respecta a las patas delanteras, el corte se produce justo por la región carpal y no por la base del radio y la ulna. Dicha circunstancia ocasiona que determinados huesos del carpo estén excluidos de la muestra, o se documenten de forma totalmente testimonial, como sucede con el piramidal, el semilunar y el pisiforme, los cuales se mantendrían unidos al resto de la extremidad, conservando la conexión con el radio y la ulna. Por contra, son muy abundantes el capitatotrapezoide, el hamato y el escafoides, los cuales conforman el plano por donde se produce el corte de las patas delanteras. Para las traseras se actúa de la misma manera, por lo que la desmembración se produce en un determinado plano de la región tarsal y no en la base de la tibia. Por este motivo apenas están representados el astrágalo y el calcáneo, que tras la sección de la extremidad quedarían unidos a la tibia. En el otro extremo se sitúa el hueso naviculocuboideo y los cuneiformes, que en el proceso de despiece pasan a formar parte de la porción que se quema en las $\operatorname{aras}^{20}$.

20 Dada la escasez de los restos de cerdos, este patrón de carnicería solo se ha podido reconstruir para cabras y ovejas. Sin embargo, las similitudes manifestadas en el tratamiento permiten pensar que el despiece aplicado a los cerdos ofrecería un modelo parecido.
Como se pone de manifiesto a partir de estos datos, el trabajo carnicero necesario para la obtención de las porciones animales responde a un modelo con unas características preestablecidas y netamente metódico en su aplicación, para el que se requiere unas habilidades específicas en relación con la anatomía animal y las fórmulas de despiece. Precisamente por esta razón, en el repertorio óseo no se registran otros huesos diferentes a los ya aludidos, a excepción de 10 casos, cuya valoración resulta absolutamente irrelevante en un espectro cuantitativo como el que caracteriza la muestra. En concreto, se trata de cinco fragmentos de calcáneo y uno de astrágalo recuperados en la estructura $\mathrm{A}, \mathrm{y}$ de un fragmento de astrágalo en la estructura C. Estos constituyen los únicos ejemplos identificados que, como ya se ha explicado, no están presentes por el tipo de despiece al que es sometido el animal. Asimismo, se han documentado tres fragmentos de vértebras, procedentes de la estructura $\mathrm{A}$, de los cuales uno se ha estimado ajeno al repertorio arqueológico; mientras que los dos restantes corresponden a la cavidad 3, asimilándose en un caso a un diminuto fragmento articular del atlas, sin poder garantizar la adscripción específica y en otro a un pequeño fragmento de vértebra de cerdo infantil.

Por lo que se refiere a las marcas de carnicería, son escasas aunque representativas del proceso de desarticulación de los animales. En este sentido, todas las huellas registradas, excepto un caso, se refieren a marcas de cortes relacionadas con la desmembración de las extremidades, cuya recurrencia es expresión sintomática de la sistematización del tratamiento carnicero. En total se han observado 31 


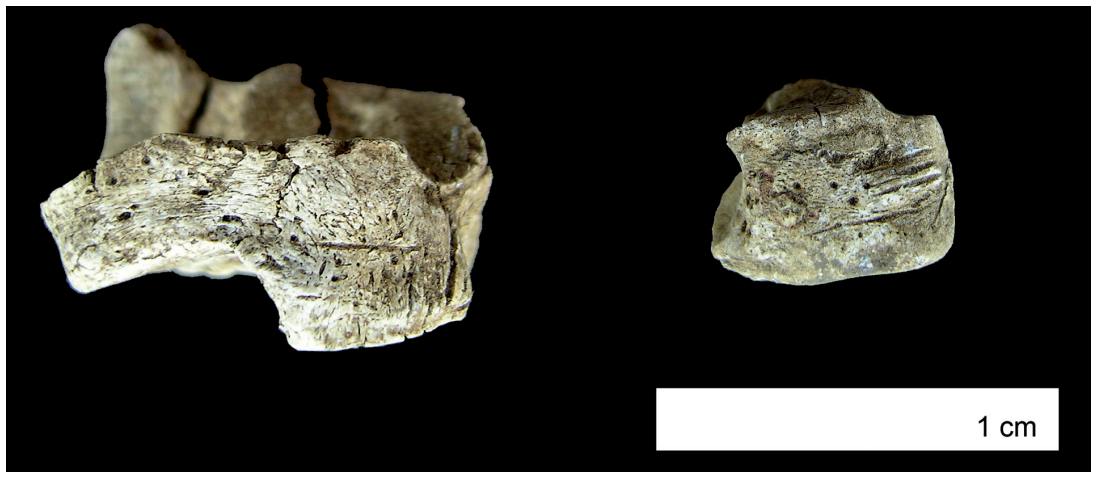

FIG. 13. Detalle del naviculocuboideo y hamato con marcas de carnicería.

índice de fragmentación. La responsabilidad de esta particular circunstancia obedece al tratamiento al que se someten los restos fáunicos en el desarrollo del ritual, esto es, la reiterada exposición al fuego. A esta situación además se unen las condiciones de exposición del espacio donde tienen lugar estos actos, haciéndolos especialmente sensibles a la afección de los agentes medioambientales, lo que se traduce en cambios de humedad y temperatura que afectan de

fragmentos con huellas de cortes, 28 de la estructura A y 3 de la c. Solo un caso corresponde a la cabeza, en concreto a un fragmento de mandíbula. Dada la condición de elemento aislado no constituye un referente significativo. Sin embargo, en otros registros como los de El Hierro se ha comprobado que en este hueso las huellas son abundantes, localizándose preferentemente en el proceso coronoides y en el cuello de la mandíbula, relacionadas con la intención de separarla de la cabeza (Alberto, 2002). Pudiera ocurrir que, dado el elevado índice de fracturación de las aras del Garajonay, las porciones de mandíbula sean tan sumamente reducidas que no permitan una fácil identificación de las huellas. De hecho hay muy pocos fragmentos correspondientes a esta región anatómica. Por otra parte, la circunstancia de que solo se registre un caso puede ser indicativa de una desigualdad en el tratamiento carnicero con respecto a las cabezas entre los registros del Garajonay y los de referencia procedentes de El Julán en la isla de El Hierro, pudiendo suceder que por algún motivo en esta se desencaje la mandíbula y en La Gomera no.

En cuanto a las extremidades (Fig. 13), en las traseras destacan las huellas constatadas en la cara dorsal del naviculocuboideo y, en menor medida, en el extremo proximal de los metatarsos. Por su parte, en las extremidades delanteras priman las marcas presentes en la cara plantar de la porción proximal del metacarpo y de forma más aislada en algún carpo.

\section{Pequeños retazos de historia}

Como se ha aludido, una de las características más representativas del registro fáunico es su elevado forma notoria a la integridad de los huesos. Directamente relacionado con las condiciones climáticas del lugar también destaca la incidencia de las formaciones vegetales, muy significativas en el caso de la estructura A.

El Garajonay, en la región cumbrera de La Gomera, se caracteriza por un clima oceánico húmedo y fresco en el que el protagonismo corresponde a los vientos alisios, causando un flujo casi constante que aporta gran humedad. Estos altos niveles repercuten en la conservación de los huesos debilitándolos, por lo que muchos de ellos, ya de por sí fragmentados por el fuego, terminan fracturándose por las líneas de debilidad de la estructura ósea. Lo mismo sucede con la vegetación, así que, en un espacio donde esta es tan importante, los procesos diagenéticos debidos a la acción de las raíces cobran gran relevancia.

Grosso modo se registra una media de fracturación en torno a los $5 \mathrm{~mm}$ de longitud. Además, un porcentaje destacado de los restos ni siquiera alcanza estas dimensiones, tal y como ocurre en el caso de las piezas dentales; si bien en el otro extremo una porción de la muestra, aunque bastante más reducida, manifiesta valores más altos entre 20 y $40 \mathrm{~mm}$ de largo, en especial en el caso de los fragmentos de diáfisis de metápodos y cuernos.

Es evidente que un repertorio con tal volumen debió estar integrado por una destacada cifra de animales. Sin embargo, el intenso grado de fracturación al que se viene aludiendo, así como la deformación que manifiestan los huesos, impiden valorar exactamente la cantidad de ejemplares que fueron sacrificados para el ritual. Con todo, se ha verificado 
un número mínimo de 34 animales (Fig. 14). En la Estructura A se reconocieron 26 ovicaprinos adultos, calculados principalmente a partir de la porción petrosa derecha (Fig. 15), el metacarpo y la mandíbula, y 3 cerdos infantiles. Mientras, en la Estructura c, considerando que el volumen de restos examinados es notoriamente menor, el resultado es de 4 ovicaprinos adultos, estimados a partir de la

\begin{tabular}{|l|c|c|c|c|c|}
\hline & \multicolumn{3}{|c|}{ Estructura A } & \multirow{2}{*}{ Estructura C } & \multirow{2}{*}{ Total NMI } \\
\cline { 2 - 5 } & cavidad 1 & cavidad 2 & cavidad 3 & & \\
\hline O/C & 4 & 2 & 20 & 4 & 30 \\
\hline Cerdos & 1 & 1 & 1 & 1 & 4 \\
\hline Total & 5 & 3 & 21 & 5 & 34 \\
\hline
\end{tabular}

FIG. 14. Reparto del NMI por estructuras. epífisis proximal del metacarpo derecho $\mathrm{y}$, al menos, un cerdo infantil. En cualquier caso, la cifra es mayor puesto que de este cómputo se han excluido los restos pertenecientes a ovicaprinos infantiles, al estar integrados fundamentalmente por diminutos fragmentos de cráneo y de diáfisis de metápodos que no resultan precisos para el cómputo.

\section{El poder de las llamas}

En general, el fuego es el principal responsable del grado de fracturación que manifiestan los restos, pero también de los destacados procesos de torsión, contracción y alteración de su coloración. Dichas modificaciones dependen de las características de la combustión, es decir, de las temperaturas alcanzadas, del tiempo de exposición, de las condiciones constructivas de la cavidad de combustión, de las circunstancias ambientales del emplazamiento, del tipo de combustible empleado, de la colocación de las porciones animales, e incluso de ciertas variables intrínsecas a la biología animal, como la especie, edad, volumen de la masa cárnica, proporción de lípidos, la arquitectura ósea, etc. (Buikstra y Swegle, 1989; David, 1990; Gilchrist y Mytum, 1986; Etxebarría, 2005; Shipman, et al., 1984; Spennemann y Colley, 1989).

Al respecto, una cuestión a destacar se deriva del emplazamiento y configuración de las estructuras. Ambas están construidas en lugares elevados, expuestos al viento, circunstancia más perceptible en la Estructura c, lo que permite avivar el fuego, aumentando su intensidad. En contrapartida, las cavidades de combustión son construcciones abiertas, totalmente expuestas a los agentes atmosféricos, situación que propicia la pérdida de energía. No obstante, el efecto limitante de las particularidades constructivas de las cavidades está parcialmente atenuado por el poder refractario de algunas de las rocas que se usan para su construcción. De hecho, durante la excavación de las cavidades de combustión y en su entorno se detectó gran número de fragmentos de lajas de basalto olivínico-augítico con evidentes signos de termoalteración. Estas losas fueron acarreadas desde un dique volcánico de la cercana Montańa de Igualero para ser empleadas en el proceso de cremación ${ }^{21}$ y poseen excelentes cualidades termoconductoras, a diferencia del basalto plagioclásico del Alto de Garajonay empleado para construir los pireos (Criado, 2005).

En cuanto a los recursos vegetales usados como combustible, según los resultados del análisis antracológico hay una gran variabilidad de especies recolectadas en distintas formaciones vegetales, especialmente desarrolladas en la vertiente sur y suroriental de la isla. No obstante, la suma de estas constituye un porcentaje bajo frente al empleo mayoritario de pino (Pinus canariensis), que es una especie escasa en La Gomera y está ausente de las formaciones de fayal-brezal y laurisilva que cubren el Alto de Garajonay y su entorno. Era su madera la que se seleccionaba para quemar las ofrendas en las aras de sacrificio de este y otros enclaves, a veces acarreándola desde considerable distancia, lo cual sugiere un especial valor simbólico más allá de sus propiedades como combustible (Machado, 2005).

Sin duda, la alteración térmica del hueso también está estrechamente vinculada al tiempo que la ofrenda es sometida al fuego, de manera que los efectos de la termoalteración se incrementan proporcionalmente al lapso de exposición. Los procesos de torsión y fracturación, comienzan a producirse de forma notoria a partir de los $600{ }^{\circ} \mathrm{C}$ (Albizuri et al., 1992; Cáceres et al., 2002; Etxebarría, 1994; Holk, 1986; Stiner et al., 1995; Reverte, 1991). Por

21 Quizá se emplearon para recubrir las paredes internas de la cavidad de combustión y/o como soporte para los despojos de animales que se ofrendaban. 


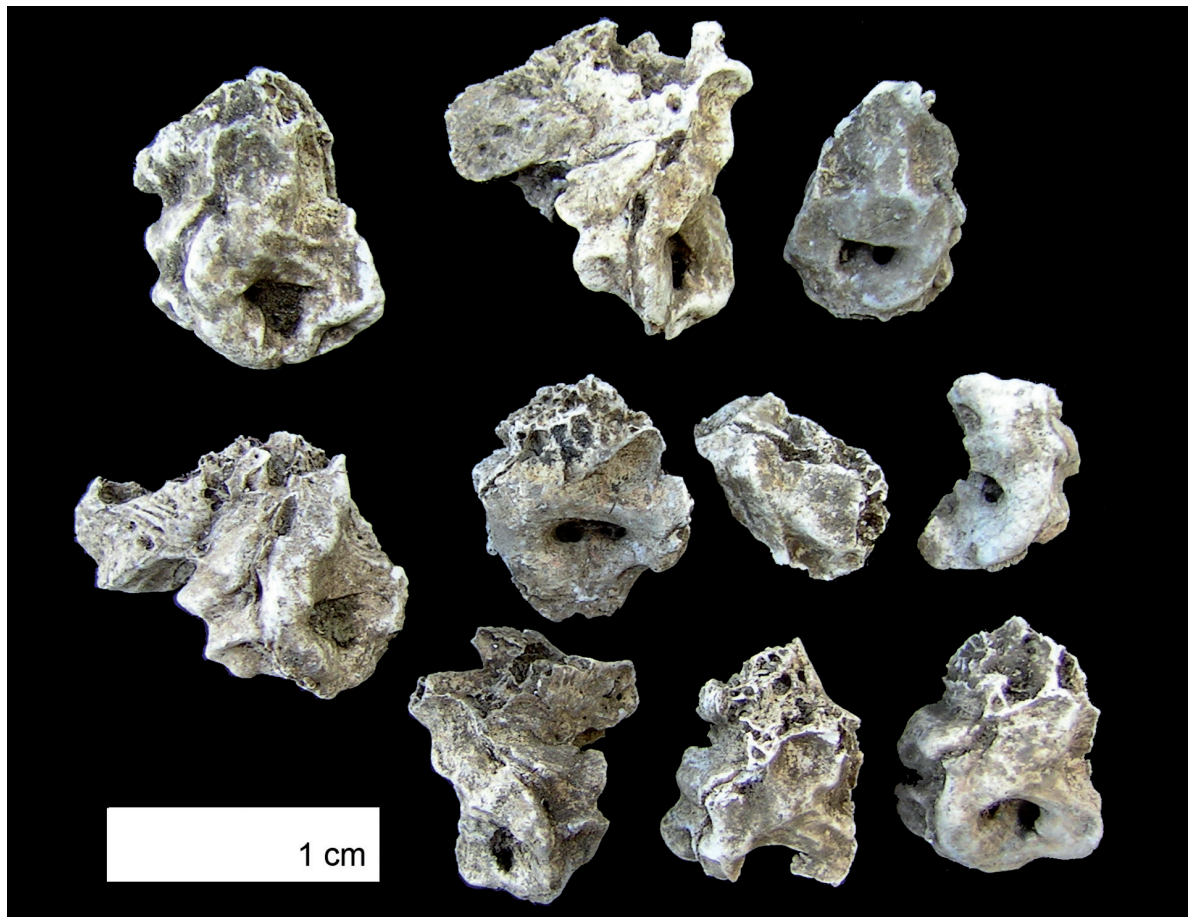

FIG. 15. Detalle de las porciones petrosas utilizadas para el cómputo del NMI.

completas. En cuanto al cráneo, su alto contenido en materia orgánica al calentarse produce un aumento de la presión haciendo que la cabeza literalmente estalle siguiendo las líneas de debilidad. Como sucede en otras aras del Archipiélago, un caso a destacar lo constituye la termoalteración de las piezas dentales. Si se valora la aportación de las regiones esqueléticas que se seleccionan para formar parte del ritual, se verifica una clara subrepresentación de la dentición, caracterizada por su escaso volumen y por su intensa fracturación. En este sentido, no se conserva ninguna pieza completa, produciéndose siempre la

lo que se refiere a la fracturación, se constata un patrón constante que afecta a los tejidos óseos en función de las especificidades morfoestructurales de cada pieza. De tal manera que el hueso fresco, como es el caso, al calentarse es sometido a una importante presión debido a la desintegración de la materia orgánica, provocando la rotura del hueso por líneas constantes o por puntos de menor resistencia. Esta es la razón por la que los fragmentos se reiteran con la misma morfología en cada unidad anatómica. Dentro de este patrón cabría destacar el predominio de las fracturas longitudinales y las curvas transversales que afectan a la diáfisis de los metápodos. Además, en estos huesos se registran los índices más elevados de deformación (Fig. 16). En las falanges primeras y segundas, aunque hay fracturas curvas transversales, son más frecuentes las longitudinales, siguiendo el mismo modelo de las diáfisis de los metápodos; mientras que las terceras se fracturan principalmente en sentido transversal. Por lo que se refiere a carpos y tarsos, constituyen las piezas óseas, junto con los sesamoideos, menos afectadas por la fracturación debido a su particular morfología, ofreciendo el porcentaje más alto de unidades separación entre la raíz y la corona, generando diminutas esquirlas de entre 1 y $2 \mathrm{~mm}$ de largo (Fig. 17). En estas piezas también se constata un modelo reiterado que se manifiesta en fracturas transversales en las raíces y longitudinales en las coronas. Según diversos ensayos a temperaturas muy elevadas los dientes experimentan intensos procesos de fracturación que pueden llegar a significar su destrucción, considerándose que en torno a los $800^{\circ} \mathrm{C}$ la calcinación de las piezas dentales es total (Etxeberría, 1994; Holk, 1986).

Otro aspecto significativo para conocer las temperaturas que se alcanzan en las aras es la pérdida de volumen óseo que se aprecia en el registro, muy evidente en el conjunto carpo-tarsal. Los procesos de contracción responden a las modificaciones estructurales en la porción mineral del hueso, en concreto a los cambios en la cristalización de hidroxiapatita que normalmente tienen lugar a partir de los $600{ }^{\circ} \mathrm{C}$ (Spennemann y Colley, 1989). Asimismo, la coloración de los huesos constituye un criterio útil para establecer las características de la combustión. En fuegos de escaso poder calorífico, de entre 200 y $300{ }^{\circ} \mathrm{C}$ o de corta duración, 
solo se produce la carbonización de los huesos, conservando así parte de la materia orgánica. Los de mayor intensidad en cuanto a temperatura y duración provocan estados de calcinación, dando lugar a la destrucción integral del tejido orgánico frente a la preservación de la fracción mineral del hueso, requiriéndose para ello temperaturas superiores a los $600^{\circ} \mathrm{C}$ (Nicholson, 1993; Hanson y Cain, 2007) ${ }^{22}$. En los huesos del Garajonay hay una prevalencia muy alta de las tonalidades gris clara o blanca, es decir, del estado calcinado, siendo prácticamente anecdóticos los de otras tonalidades tales como el gris oscuro, marrón e incluso el negro (Fig. 18).

Al margen de estos criterios, para considerar la calidad de la combustión se ha de valorar la posibilidad de que

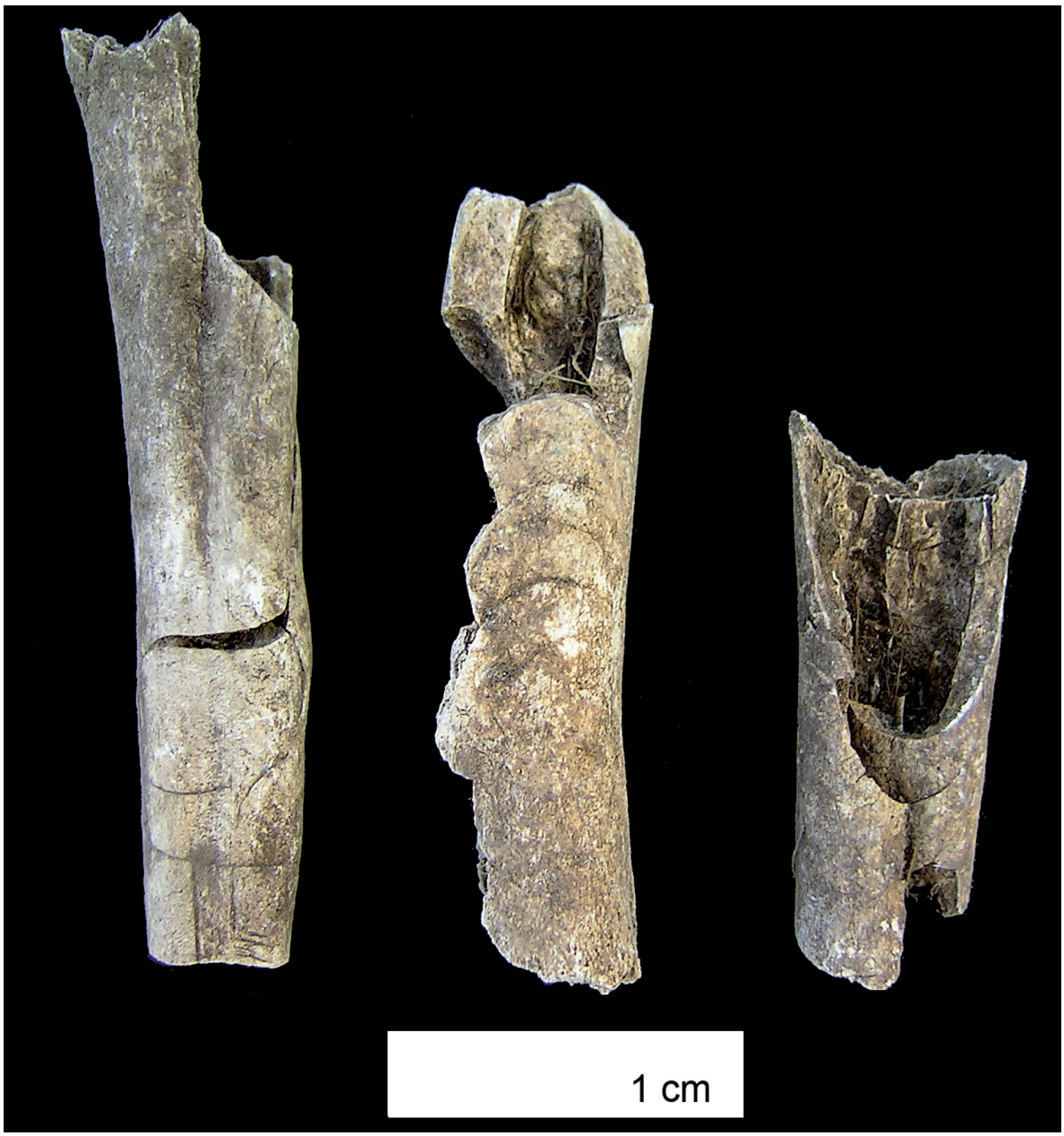

FIG. 16. Detalle de los procesos de fracturación y torsión en los metápodos.

en sucesivas cremaciones muchos de los huesos ya quemados, correspondientes a anteriores celebraciones, se ven reiteradamente afectados por la acción térmica, produciendo nuevas alteraciones. Los fenómenos de torsión y las fracturas transversales curvas de las diáfisis son sintomáticos de la combustión de huesos frescos, revestidos de partes blandas, sin que para ello se requiera alcanzar un nivel calorífico extremo. Sin embargo, en la mayor parte de los restos se detectan fracturas longitudinales indicativas de temperaturas más altas, por encima de los $600{ }^{\circ} \mathrm{C}$. Se acepta que los huesos

22 Si bien estudios experimentales han revelado que a temperaturas más bajas, si la duración de la exposición se prolonga, también se produce la calcinación (Bennett, 1999). frescos presentan un índice de fracturación mayor, dándose un predominio de los planos transversales, mientras que los huesos secos lo hacen principalmente en sentido longitudinal. Así, la preponderancia de este último tipo es un indicio revelador de altas temperaturas, pero también de la posibilidad de que los huesos se termoalteren en sucesivas reutilizaciones del ara. Además, en relación con las temperaturas, ha de valorarse que los huesos que aún conservan cierta materia orgánica, aun después de haber perdido la masa cárnica que los recubre, actúan como un potenciador de la combustión. De tal manera que al alcanzar los $500{ }^{\circ} \mathrm{C}$ favorece el mantenimiento del fuego durante un tiempo prolongado, elevando las temperaturas en una combustión lenta (Etxeberría, 1994; Théry-Parisot, 2002; Yravedra et al., 2005). 


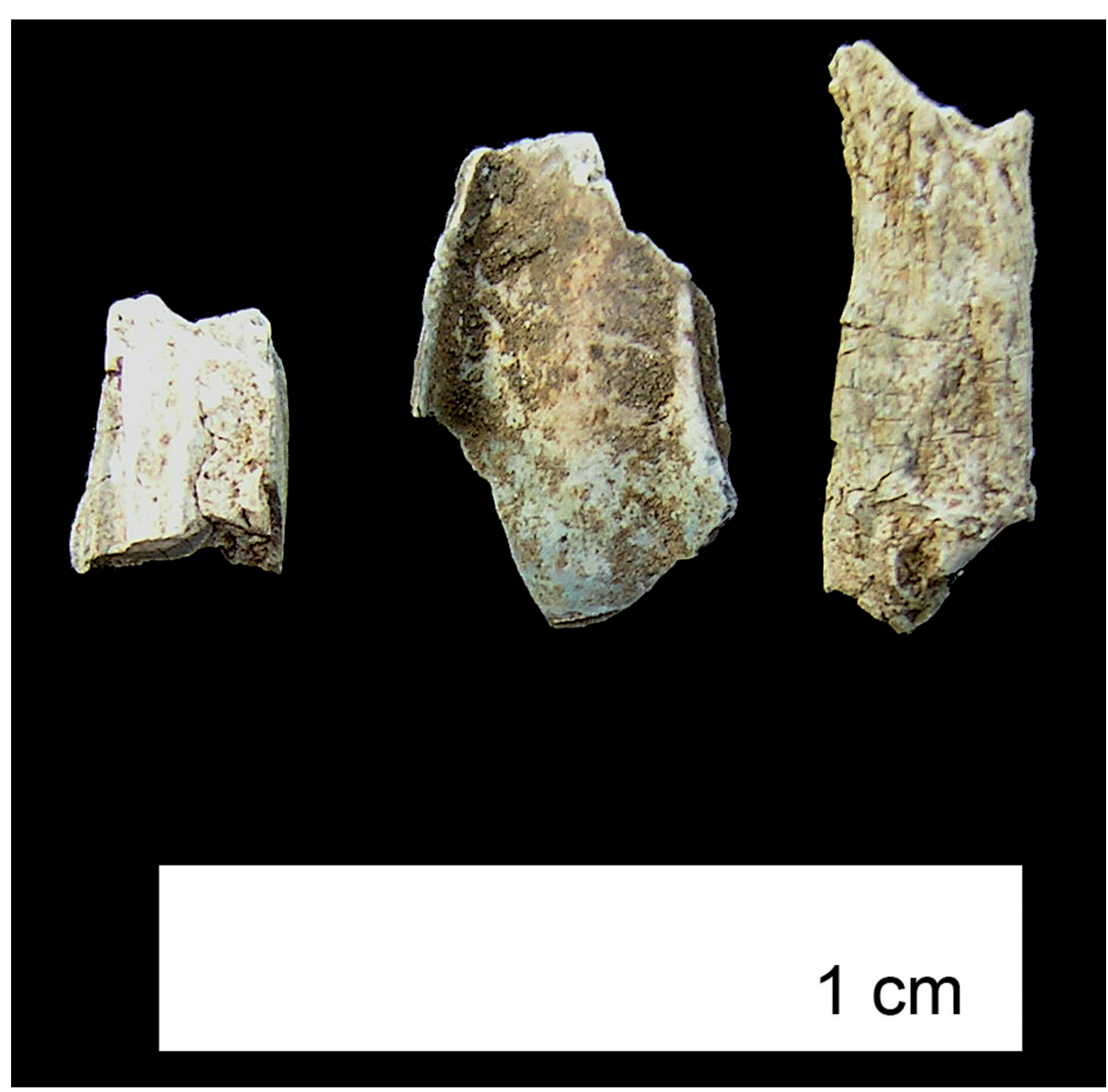

FIG. 17. Detalle del nivel de fracturación de las piezas dentales.

\section{Animales para la estabilidad social}

El repertorio fáunico del Garajonay, como el de otras aras de sacrificios de La Gomera y El Hierro, está integrado en su totalidad por animales domésticos: cabras, ovejas y, a mucha distancia, cerdos. Se trata de un componente esencial en la subsistencia directa de los antiguos pobladores de la isla. Sin embargo, más allá de la condición de proveedor de alimentos básicos en la dieta aborigen, representa un fundamento prioritario de las bases del proceso productivo y relaciones sociales que para la ocasión se gestiona bajo el prisma de las creencias. Se observa un claro predominio de animales desarrollados, aunque también están presentes ejemplares infantiles, in-

En una valoración global se pone de manifiesto que las temperaturas y el tiempo de exposición que definen la combustión en el Garagonay se sitúan en niveles considerables que pueden superar los $600{ }^{\circ} \mathrm{C}$. Por su parte, la intensa fragmentación de los dientes, asimilable a temperaturas cercanas a los $800^{\circ} \mathrm{C}$, pudiera explicarse no porque se alcancen tales niveles, difíciles de obtener en fuegos de estas características, sino por la afección reiterada a la fuente de calor que termina fragmentando las piezas previamente fisuradas. En términos generales, las evidencias de termoalteración en los restos óseos son lo suficientemente contundentes como para considerar la realización de fuegos intensos, bien organizados, en los que se alcanzan temperaturas elevadas y se mantienen activos durante un tiempo que, sin poder precisar con exactitud, no parece ser breve. cluidos los recién nacidos. Asimismo, el porcentaje mayoritario corresponde a las hembras, sin excluir la posibilidad de que una porción importante de ejemplares masculinos pudieran encontrarse en el grupo de los infantiles. Este patrón de sacrificio coincide en gran medida con las pautas generales de explotación y aprovechamiento alimenticio de la cabaña ganadera de los primeros canarios; sin perjuicio de otras posibilidades más específicas entre las normas de selección que pudieran haber tenido lugar con motivo de un evento especial ${ }^{23}$.

23 Como así se ha estimado para otros muchos contextos rituales donde solo se sacrifican ejemplares infantiles, solo machos, etc. Ello no es óbice para considerar que dentro de los criterios que determinan la elección de las víctimas se prefieran determinados animales en función de algún atributo que en la actualidad no es factible identificar, tales como color, procedencia, crianza con arreglo a unos parámetros concretos, etc. 
Además de los datos de orden biológico o estrictamente anatómicos, para profundizar en la organización del ritual es ineludible abordar el tratamiento al que es sometido el animal. En este sentido se entiende la selección de ciertas partes del cuerpo, aquellas de menor aprovechamiento para el consumo humano, la precisa manipulación aplicada para obtener las porciones de interés en el rito y la notable trascendencia que adquiere el fuego en dicho proceso; revelando una estricta regulación de los gestos que toda celebración ritual entraña, acorde a un código social

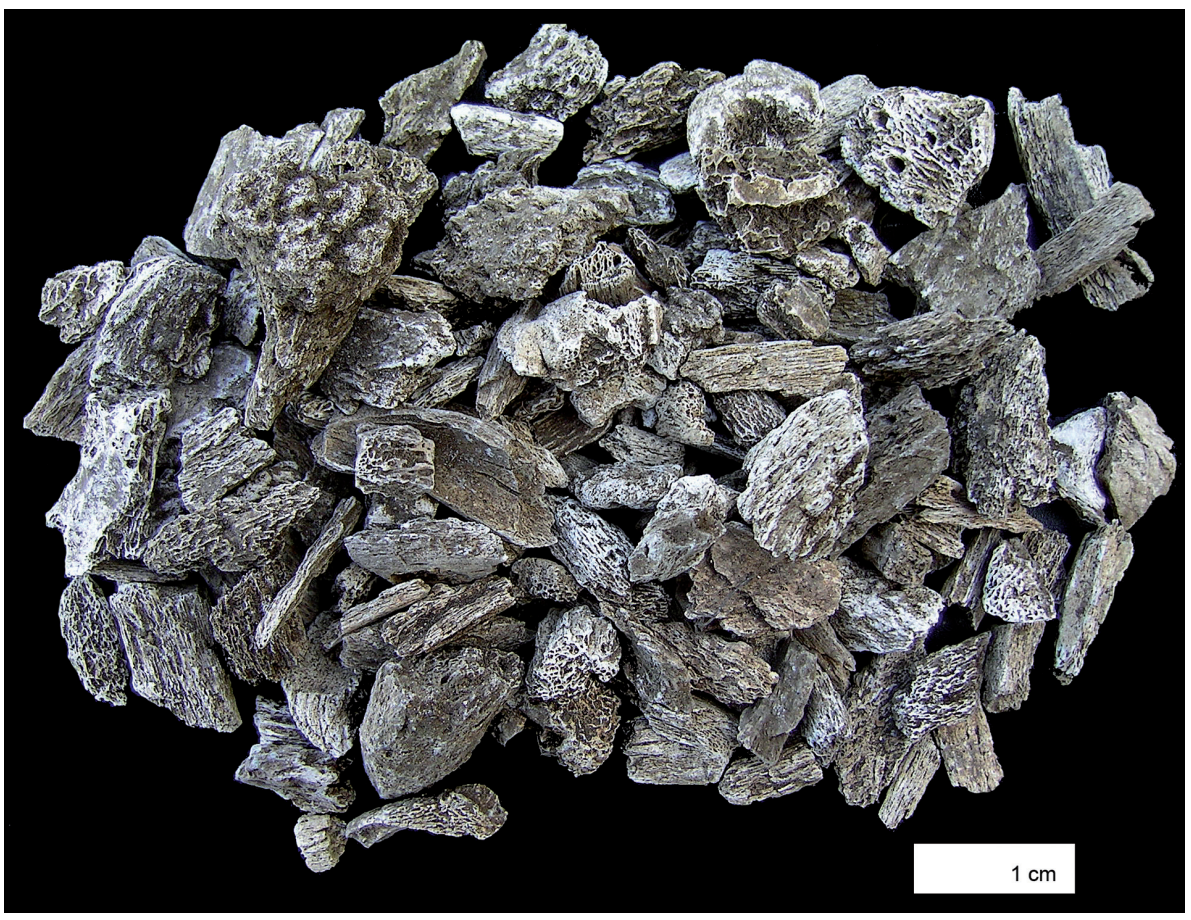

FIG. 18. Fragmentos de cuernos calcinados. asumido por el colectivo.

La tarea de desmembrar

las víctimas de una manera tan sistemática requiere de una precisión y experiencia que podría interpretarse como la evidencia de un trabajo especializado. $\mathrm{Si}$ a ello se une la participación de otras personas adiestradas en distintas parcelas $u$ oficios destinadas a diversas ocupaciones en relación con el mantenimiento del sitio y la práctica ritual, se vislumbra un panorama escrupulosamente planificado que es reflejo de la complejidad que revisten las fórmulas de organización social del trabajo. Así parecen revelarlo las particularidades de la industria lítica, asociada preferentemente a las actividades de mantenimiento y adecuación de las construcciones cultuales y su entorno, pues no hay que olvidar que el complejo se halla inserto en el bosque, donde las tareas de deforestación debieron ser constantes. En menor medida, se documenta un repertorio que pudiera estar relacionado con ciertas actividades carniceras según se desprende de las huellas de uso identificadas. Más difícil de entender es el hecho de que algunas piezas aparezcan dentro de las cavidades de combustión. Resulta complejo discernir si ello responde a un gesto intencional o acciones casuales, si bien, teniendo en cuenta la elevada normalización de los patrones descritos y el carácter ritualizado de unos gestos que se repitieron una y otra vez de manera sorprendentemente constante, no resulta descabellado pensar que también tengan un sentido simbólico, máxime si como parece la producción lítica llevada a cabo en este ámbito está motivada única y exclusivamente por las actividades allí desarrolladas. Al efecto, en el Alto de Garajonay se genera y consume la producción lítica en todas sus fases (captación, fabricación, uso y abandono), en otros términos, 'se talla para las aras'. Los restos líticos corresponden a diversos momentos de las cadenas operativas desplegadas para crear instrumentos de trabajo en las inmediaciones de donde iban a ser empleados, resultando un repertorio constituido por restos de talla (lascas, fragmentos y núcleos) y por los propios útiles que serían abandonados en el lugar, una vez hubieran cumplido su función, incluso en la posible categoría de ofrenda (Hernández y Rodríguez, 2005).

Ya seleccionadas las porciones animales para la ceremonia, da comienzo el verdadero evento litúrgico que se lee en el registro arqueológico de las aras de sacrificio. Aquí el fuego representa un apartado 
esencial de la función. Podría considerarse como el procedimiento mediante el cual se quema parte del animal, si bien esta clase de celebraciones implica toda una serie de actos y concepciones que superan netamente el hecho de quemar y donde casi seguro la jornada de celebración incluiría otras actividades que no dejaron una huella tan explícita en el registro arqueológico.

Dentro de este contexto, se ha de aludir al destino de las porciones animales que no arden en el fuego. Es evidente que las partes que se seleccionan para el culto coinciden con aquellas que representan un menor aporte cárnico. Tales porciones, cabeza y extremo de las patas, son frecuentemente utilizadas en numerosos contextos rituales en la categoría de ofrendas quemadas o no, en ambientes donde subyace un notable contenido simbólico (Albizuri, 2011; Belarte y Valenzuela, 2013; Liesau, 2012), o como es el propio caso de cuevas funerarias aborígenes del Archipiélago canario (Alberto, 1999; Alberto y Velasco, 2003; Velasco et al., 2005). Por tanto, puede considerarse que, al margen de constituir las tajadas de menor interés alimenticio, esta selección tiene un significado preciso en el código que define el ritual y que hoy resulta complejo interpretar. Pero si difícil es comprender por qué se eligen estas pedazos y no otros, más enigmático resulta el destino del resto del animal. Sobre este particular no es extrańo que junto a rituales de ofrendas quemadas se lleven a cabo banquetes o festines "sagrados", en los que se consuman la carne y vísceras de las víctimas, de las que se separan las raciones entregadas a la divinidad (Ekrotht, 2009; Green, 2002). Sin embargo, en el ejemplo que nos ocupa, no existe el menor indicio para considerar este tipo de comidas rituales o prácticas de comensalidad, por lo menos en lo que al entorno inmediato de las aras atańe.

Otra cuestión es discernir si los animales se sacrifican y procesan allí mismo, lo que implicaría que el resto del cuerpo que no se usa en las aras finalmente terminara siendo trasladado hacia otros enclaves, o si las piezas se llevan ya preparadas desde otro lugar, ya sea los propios ámbitos domésticos, bien algún centro específico de procesado para la obtención de esta clase de productos. En este tipo de celebraciones en ocasiones se produce la distribución de la víctima entre los miembros activos del ritual o las personas que en él participan, a partir del reparto de unas porciones preestablecidas según un criterio de orden social. Pudiera plantearse el desarrollo de un acto redistributivo en el marco de las relaciones sociales de producción de los antiguos gomeros, como así se recoge en las fuentes documentales para otras islas del Archipiélago (Galván et al., 1999), con independencia de que se lleve a efecto en el sitio de forma real o se refiera al acontecimiento de ratificar la norma. Igualmente, puede considerarse una fórmula de sanción sobre el consumo de carne u otros bienes de origen animal. En cualquier caso, todos los indicios apuntan a que en las aras solo se encuentran las porciones que se consumen en el fuego.

Los sacrificios animales, en forma de cabezas y patas que se queman en un lugar específico a modo de altar, son interpretados como ofrendas a la divinidad. Por tanto, se enmarcan en una celebración de carácter mágico-religioso que, dada la naturaleza principal del santuario de Garajonay, entraña una gran carga simbólica en el marco de las estructuras ideológicas de las poblaciones gomeras. El servicio, consistente en el acto de quemar, es entendido como el establecimiento de un vínculo de comunicación entre lo mundano y lo sagrado, en el que los animales funcionan como elementos intermediarios de conexión, para lo cual se selecciona como combustible un árbol raro en la isla, el pino, que posiblemente tuviera también una particular carga simbólica.

Las aras de sacrificio de La Gomera, en especial las del Alto de Garajonay, son espacios colectivos sumamente complejos, donde se materializa la gestión de las relaciones interpersonales y se proyectan los mecanismos de perpetuación, bajo un enfoque sagrado. Se interpreta que estos espacios tuvieron una larga vigencia temporal a partir de las sucesivas utilizaciones y readecuaciones que se identifican en las estructuras. En sus fuegos se consumieron productos esenciales en la vida de los antiguos gomeros, donde los animales domésticos, pero también los productos vegetales, suministraron las bases principales de los bienes ofrendados.

Conocemos algunos de los gestos que participaron de esta cuidada escenificación, incluso podemos intuir otros como el empleo del canto o la entrada en estados de trance, como observaron los conquistadores en la isla de El Hierro (Fructuoso, 1964: 132). Pero el fin desencadenante no se desvela tan claramente. Al respecto, se ignora qué condiciones han de darse para que se lleven a cabo este tipo de celebraciones, cuándo y quiénes fueron los artífices reales de tales eventos. No obstante, según los relatos recogidos en las crónicas 
de la conquista, cabría la interpretación de ceremonias a modo de rogativa, buscando la intercesión favorable de la divinidad, siendo muy frecuentes en todas las culturas prehispánicas insulares los rituales colectivos para la solicitud de lluvia, vinculados con la fertilidad de los campos y el crecimiento de los pastos de los que se alimentan los rebaños (Tejera y Montesdeoca, 2004). A ello se suman las referencias de las fuentes escritas, donde se alude a la quema de productos alimenticios en prácticas premonitorias en relación con lo que ha de acontecer, en un diálogo con la divinidad que se manifiesta mediante el humo de la combustión (Alberto, 2002; Navarro, 2006 y 2007). Tales relatos, en el caso de La Gomera, señalan directamente a un ser supremo, "Señor y creador de todas las cosas", al que entregaban un "diezmo" de los frutos de que este les proveía. Se trata de actividades que poseen un carácter colectivo, sin precisar cuál es su representación exacta, pero donde la figura de personajes relevantes en el orden social, líderes políticos y religiosos, ostenta una posición dominante. Sobre este aspecto es muy significativo el rol de los adivinos gomeros, algunos de los cuales quedaron inmortalizados en las fuentes etnohistóricas. “... tuvieron hombres fatídicos, que predecían lo que había de ocurrir; y entre ellos se menciona a uno llamado Eiunche, que les daba a entender que en el cielo había un Dios llamado Orahan, quien había hecho todas las cosas ..." (Torriani, 1959 [1594]: 204) “... de parte de aquel Señor de Sobre Todo a quien ellos daban aquel diezmo que quemaban..." (Del Castillo, 1948-1950 [1737]: 206-207).

En la práctica social se sustentan los criterios de ordenación y uso del territorio y al respecto el conjunto del Garajonay se entiende como un santuario de primer orden, de alcance insular, alejado de cualquier asentamiento humano estable, enclavado en un espacio distintivo y distinguido, es decir, en el centro geográfico y cúspide de la isla. A este se suma una estructurada red de lugares de culto con aras de sacrificio, en un sistema jerarquizado que, junto con los rangos intermedios y locales, son expresión de la globalización del fenómeno. Si se considera la posición del Garajonay en este modelo, asimismo cabe la interpretación de un espacio con sentido de agregación social, donde confluyen representantes de los diversos bandos o facciones en que se organizaba la población de La Gomera.

\section{Bibliografía}

Alberto, V. (1999): “Los animales en las prácticas funerarias guanches", Anuario de Estudios Atlánticos, 51, pp. 19-60.

Alberto, V. (2002): "Los animales en el ritual. A propósito de un ara de sacrificio de El Julan (La Frontera, El Hierro)". En Hernández, M.: El Julan. Estudios Prehispánicos, 10. Santa Cruz de Tenerife: Gob. de Canarias, pp. $125-146$.

Alberto, V. (2004): “De carne y hueso. La ganadería en época prehispánica”, El Pajar. Cuaderno de Etnografía Canaria: la Ganadería el Hombre y el Medio, 18, pp. 4-8.

Alberto, V. y Velasco, J. (2003): “A propósito del fuego en los contextos funerarios prehispánicos de Canarias. Apuntes para su explicación cultural", Tabona, 12, pp. 97-118.

Albizuri, S. (2011): “Depósitos de ovicaprinos en ámbito doméstico ibérico. El ejemplo del poblado de Ca n'Oliver (Cerdanyola del Vallès, Barcelona)", Archaeofauna, 20, pp. 85-101.

Albizuri, S.; Colomer, S. y Buisan, C. (1992): "Experimentación sobre la exposición del tejido óseo a focos de calor", Estudios de la Antigüedad, 6, pp. 91-97.

Belarte, M. C. y Valenzuela-Lamas, S. (2013): “Zooarchaeological evidence for domestic rituals in the Iron Age communities of North-Eastern Iberia (present-day Catalonia) (sixth-second century BC)", Oxford Journal of archaeology, 32 (2), pp. 163-186.

Bennet, J. L. (1999): "Thermal alteration of buried bone", Journal of Archaeological Science, 26, pp. 1-8.

Boessneck, J. (1980): "Diferencias osteológicas entre las ovejas (Ovis aries Linné) y cabras (Capra hircus Linné)”. En Brothwell, D. R. y Higgs, E. (eds.): Ciencia en Arqueología. México: FCE, pp. 338-366.

BRÜCK, J. (1999): "Ritual and rationality: some problems of interpretation in European archaeology", European Journal of Archaeology, 2 (3), pp. 313-344.

Buikstra, J. E. y Swegle, M. (1989): "Bone modification due to burning experimental evidence”. En BonNichSEn, R. y Song, M. (eds.): Bone Modification. Orono: Institute for Quaternary Studies, Univ. of Maine, pp. 247-258.

Cáceres, I.; Bravo, P.; Esteban, M.; Expósito, I. y SALADIÉ, P. (2002): "Fresh and heated bones breakage. An experimental approach”. En De Rienzi, M. (ed.): Current topics on taphonomy and fossilization. Col.lecció Encontres, 5. Valencia, pp. 471-481.

Clason, A. T. (1972): "Some remarks on the use and presentation of archaeozoological data", Helinium, 12 (2), pp. 139-153.

Criado, C. (2005): "Estudio geoarqueológico del Alto de Garajonay". En Navarro, J. F.; Hernández, J. C.; Hernández, C.; Borges, E.; Barro, A. y Alberto, V. (2005): Inventario arqueológico y su aplicación a la conservación e incorporación a los programas interpretativos 
178 Verónica Alberto, Juan Francisco Navarro y Pablo Castellano / Animales y ritual. Los registros fáunicos de las aras...

del Parque Nacional de Garajonay. Memoria de las excavaciones arqueológicas. Univ. La Laguna-Parques Nacionales.

DAvid, B. (1990): "How was this bone burnt?". En Solomon, S.; Davidson, I. y Watson, D. (eds.): "Problem solving in taphonomy", Tempus, 2, pp. 65-79.

DAvis, S. (2008): "Thou shalt take of the ram...the right thigh; for it is a ram of consecration... Some zoo-archaeological examples of body part preferences". En D'Andria, F.; De Grossi, J. y Fiorentino, G. (eds.): Uomini, piante e animali nella dimensione del sacro. Bari: Edipuglia, pp. 63-70.

Del Castillo, P. A. (1948-1950): Descripción histórica y geográfica de las Islas Canarias. Edic. crítica de Miguel Santiago. Madrid.

Екrотнт, G. (2009): “Thighs or tails? The osteological evidence as a source for Greek ritual norms". En BruLÉ, P. (ed.): La norme en matière religieuse. Kernos supp., 21. Liège, pp. 125-151.

ETXEBerRía, F. (1994): “Aspectos macroscópicos del hueso sometido al fuego. Revisión de las cremaciones descritas en el País Vasco desde la arqueología”, Munibe, 46, pp. 11-116.

Etxeberría, F. (2005): "Estudio de los resultados del proyecto de arqueología experimental sobre la clausura de la tumba monumental de La Peńa de la Abuela (Ambrona, Soria)". En Rojo, M.; Kunst, M.; Garrido, R.; García Martínez de Lagrán, I. y Morán, G. (eds.): Un desafio a la eternidad. Tumbas monumentales del Valle de Ambrona. Memorias Arqueología en Castilla y León, 14. Valladolid, pp. 269-278.

Fructuoso, G. (1964): Las islas Canarias (de Saudades da Terra). La Laguna.

Galván, B.; Hernández, C.; Velasco, J.; Alberto, V.; Borges, E.; Barro, A. y Larraz, A. (1999): Los orígenes de Buenavista del Norte. De los primeros pobladores a los inicios de la población europea. Santa Cruz de Tenerife: Ayto. Buenavista del Norte.

Gilchrist, R. y Mytum, H. (1986): "Experimental archaeology and burnt animal bone from archaeological sites", Circaea, 4, pp. 29-38.

Grant, A. (1982): Ageing and sexing animal bones from archaeological sites. BAR British Ser., 109. Oxford, pp. 90-108.

Green, M. (2002): Animals in Celtic Life and Myth. London: Routledge.

Hanson, M. y Cain, C. R. (2007). "Examining histology to identify burned bone", Journal of Archaeological Science, 34 (11), pp. 1902-1913. http://dx.doi.org/10.1016/j.jas.2007.01.009

Hernández, C. M. y Rodríguez, A. (2005): "La industria lítica”. En Navarro, J. F.; Hernández, J. C.; Hernández, C.; Borges, E.; Barro, A. y Alberto, V.: Inventario arqueológico y su aplicación a la conservación e incorporación a los programas interpretativos del Parque
Nacional de Garajonay. Memoria de las excavaciones arqueológicas. Univ. La Laguna-Parques Nacionales.

Hernández, J. C. y Navarro, J. F. (2011-12): "Arqueología del territorio en La Gomera (Islas Canarias)", Tabona, 19, pp. 25-58.

Holk, P. (1986): Cremated bones. A medica-anthropological studied of an archaeological material on cremationes buriels. Antropologiske Skrifter, 1. Oslo: Univ. Oslo.

JiméNez, M. C. (1993): El Hierro y los bimbaches. Santa Cruz de Tenerife: Centro de la Cultura Popular Canaria.

Liesau, C. (2012): "Depósitos con ofrendas de animales en yacimientos de Cogotas I. Antecedentes y características". En Rodríguez, J. y Fernández, J. (eds.): Cogotas I. Una cultura de la Edad del Bronce en la península Ibérica. Valladolid: Univ. Valladolid, pp. 219-257.

Machado, M. C. (2005): "Estudio antracológico de las evidencias de combustible recuperadas en las excavaciones del Alto de Garajonay". En Navarro, J. F.; Hernández, J. C.; Hernández, C.; Borges, E.; Barro, A. y Alberto, V.: Inventario arqueológico y su aplicación a la conservación e incorporación a los programas interpretativos del Parque Nacional de Garajonay. Memoria de las excavaciones arqueológicas. Univ. La Laguna-Parques Nacionales.

Morales, J. (2008): “Zooarqueología en un contexto ritual: posibilidades de estudio y ejemplos de aplicación en el Mediterráneo". En Ferrer, E.; Mazuelos, J. y EscaCENA, J. (eds.): De dioses y bestias. Animales y religión en el mundo antiguo. Spal Monografías, n. ${ }^{\circ} 11$, pp. 13-31.

Morales J.; Navarro, J. F. y Rodríguez, A. (2009): “Plant offerings to the Gods: seed remains from a pre-hispanic sacrificial altar in La Gomera island". En FAHMY, A. G.; Kahlheber, S. y D'Andrea, K. (eds.): Windows on the African Past. Current approaches to African Archaeobotany. Proceeding to the $6^{\text {th }}$ International Workshop on Africa Archaeobotany. El Cairo, pp. 67-78.

Navarro, J. F. (1992): Los Gomeros una prehistoria insular. Estudios Prehispánicos, 1. Santa Cruz de Tenerife: Gob. Canarias.

Navarro, J. F. (2003): "Arqueología en el Parque Nacional de Garajonay", Parques Nacionales. Ambienta, 26, pp. $18-21$.

Navarro, J. F. (2004): "Espacios sagrados en las religiones aborígenes", Almogaren, 34, pp. 21-38.

NAVARRO, J. F. (2006): "Lugares mágicos, territorios para la reproducción social: el caso de la isla de La Gomera”, El Pajar. Cuadernos de Etnografía, II época, 21, pp. 77-87.

Navarro, J. F. (2007): "Santuarios y espacios sacralizados entre los antiguos canarios", Veleia, 24-25, pp. 12571272.

Navarro, J. F.; Borges, E.; Barro, A.; Alberto, V.; HerNÁNDEZ, C. M. y Hernández, J. C. (2001a): "El diezmo a Orahan: pireos o aras de sacrificio en la Prehistoria de La Gomera (Islas Canarias)", Tabona, 10, pp. $91-126$. 
Navarro, J. F.; Hernández, C. M.; Alberto, V.; Borges, E.; Barro, A. y Hernández, J. C. (2001b): "Aras de sacrificio y grabados rupestres en el Lomo del Piquillo (La Gomera)", Anuario del Instituto de Estudios Canarios, XLV, pp. 317-340.

Navarro, J. F.; Hernández, C. M.; Barro, A.; Borges, E.; Hernández, J. C. y Alberto, V. (2001c): "La fortaleza de Chipude y los concheros de Arguamul al cabo de tres décadas. Viejos problemas, nuevas interpretaciones", SPAL, 10, pp. 327-341.

Navarro, J. F.; Hernández, J. C.; Hernández, C.; AlBerto, V.; BARro, A. y Borges, E. (2002): Investigaciones arqueológicas en el Alto de Garajonay (Parque Nacional de Garajonay). Memoria. Univ. La Laguna-Parques Nacionales.

Navarro, J. F.; Hernández, J. C.; Hernández, C.; Borges, E.; Barro, A. y Alberto, V. (2005): Inventario arqueológico y su aplicación a la conservación e incorporación a los programas interpretativos del Parque Nacional de Garajonay. Memoria. Univ. La Laguna-Parques Nacionales.

Nicholson, R. A. (1993): "A morphological investigation of burnt animal bone and an evaluation of its utility in archaeology", Journal of Archaeological Science, 20, pp. 411-428.

PAIs, J. (1996): La economía de producción en la Prehistoria de la isla de La Palma. La ganadería. Estudios prehispánicos, 3. Santa Cruz de Tenerife: Gob. de Canarias.

Payne, S. (1973): "Kill-off patterns in sheep and goats: the mandibles from Asvan Kale", Anatolian Studies, 23, pp. 281-303.

PaYne, S. (1987): "Reference codes for wear states in the mandibular cheek teeth of sheep and goats", Journal of Archaeological Science, 14, pp. 609-614.

Reverte, J. M. (1991): Antropología forense. Madrid: Ministerio de Justicia.

Shipman, P.; Foster, G. y Schoenninger, M. (1984): "Burnt bones and teeth: an experimental study of color, morphology, crystal structure and shrinkage", Journal of Archaeological Science, 1, pp. 307-325.

Silver, I. A. (1980): “The ageing of domestic animals". En Brothwell, D. R. y Higgs, E. S. (eds.): Ciencia en Arqueología. México: FCE, pp. 289-309.

Spennemann, D. y Colley, S. (1989): "Fire in a pit the effects of burning on faunal remains", Archaeozoologia, III, pp. 51-64.

Steiner, H. (2007): "Aras de sacrificio en El Julan, El Hierro (I): lugares de sacrificio en el entorno de Los Letreros", El Museo Canario, LXII, pp. 77-126.

Steiner, H. (2008): "Aras de sacrificio en El Julan, El Hierro (II): lugares de sacrificio en el entorno de Los Letreros", El Museo Canario, LXIII, pp. 47-84.

Steiner, M. C.; Kuhn, S. L.; Weiner, S. y Bar Yosef, O. (1995): "Differential burning, recrystalisation, and fragmentation of archaeological bone", Journal of Archaeological Science, 22, pp. 223-237.

Tejera, A. y Montesdeoca, M. (2004): Religión y mito de los antiguos canarios. La Laguna: Artemisa Edit.

Théry-Parisot, I. (2002): "Fuel management (bone and wood) during the Lower Aurignacian in the Pataud Rock Shelter (Lower Paleolithic, Les Eyzies de Tayac, Dordogne, France). Contribution of experimentation", Journal of Archaeological Science, 29, pp. 1415-1421. http://dx.doi.org/10.1006/jasc.2001.0781

Torriani, L. (1959 [1594]): Descripción e Historia del reino de las Islas Canarias, antes Afortunadas, con el parecer de sus fortificaciones. Santa Cruz de Tenerife: Goya Edit.

Velasco, J.; Ruiz, M. y Sánchez, S. (2005): El lugar de los antepasados. La necrópolis bimbache de montaña Lajura. Valverde: Cabildo Insular de El Hierro.

Yravedra, J.; Aena, J.; Arrizabalaga, A. e Yriarte, M. J. (2005): "El empleo de material óseo como combustible durante el Paleolítico Medio y Superior en el Cantábrico. Observaciones experimentales", Museo de Altamira, Monografías, n. ${ }^{\circ} 20$, pp. 369-383. 
